\title{
The Vanishing Procyclicality of Labor Productivity*
}

\author{
Jordi Galí \\ CREI, Universitat Pompeu Fabra and Barcelona GSE \\ jgali@crei.cat \\ Thijs van Rens \\ CREI, Universitat Pompeu Fabra and Barcelona GSE \\ tvanrens@crei.cat
}

This version: July 2010

First version: August 2008

\begin{abstract}
We document three changes in postwar US macroeconomic dynamics: $(i)$ the procyclicality of labor productivity has vanished, $(i i)$ the relative volatility of employment has risen, and ( $i i i)$ the relative (and absolute) volatility of the real wage has risen. We propose an explanation for all three changes that is based on a common source: a decline in labor market frictions. We develop a simple model with labor market frictions, variable effort, and endogenous wage rigidities to illustrate the mechanisms underlying our explanation. We show that the reduction in frictions may also have contributed to the observed decline in output volatility.
\end{abstract}

Keywords: labor hoarding, labor market frictions, wage rigidities, effort choice JEL classification: E24 E32

\footnotetext{
${ }^{*}$ We have benefited from comments and suggestions by Almut Balleer, Paula Bustos, Vasco Carvalho, Wouter Denhaan, Jan Eeckhout, Ester Faia, Claudio Michelacci, Kris Nimark, Evi Pappa, Giorgio Primiceri, Ayşegül Şahin, Carlos Thomas, Jaume Ventura, Joachim Voth, Eran Yashiv and participants in the CREI Macro Faculty Lunch, NBER Summer Institute, EES research network workshop in Kiel, CEPR-RIETI Workshop on "Labor Markets and the Macroeconomy" in Tokyo, University of Amsterdam, Malaga Workshop on "Labor Market Frictions", European Central Bank, Norges Bank, CPB, ECB-CEPR Workshop on "European Labor Market Adjustment", Sabanci University, ESSIM 2010 and SED 2010. Davide Debortoli provided outstanding research assistance. We gratefully acknowledge financial support from the European Research Council, the Spanish Ministry of Science and Innovation (grants SEJ2006-02235, ECO2008-01665, CSD2006-00016 and Juan de la Cierva); the Generalitat de Catalunya (DIUE grant 2009SGR1157); and the Barcelona GSE Research Network.
} 


\section{Introduction}

The nature of business cycle fluctuations changes over time. There is a host of evidence for changes in the dynamics of postwar US macroeconomic time series (Blanchard and Watson (1986), McConell and Pérez-Quirós (2000), Stock and Watson (2002), Hall (2007), Galí; and Gambetti (2009)). The present paper documents and discusses three aspects of these changes:

- The correlation of labor productivity with output or labor input has declined, by some measures dramatically so. ${ }^{1}$

- The volatility of labor input measures has increased (relative to that of output). ${ }^{2}$

- The volatility of real wage measures has increased, both in relative and absolute terms. ${ }^{3}$

All three of the above observations point towards a change in labor market dynamics. While each may be of independent interest and have potentially useful implications for our understanding of macro fluctuations, our goal in the present paper is to explore their possible connection. In particular, we seek to investigate the hypothesis that all three changes may be driven by an increase in labor market flexibility, allowing firms to adjust their labor force more easily in response to various kinds of shocks. In order to illustrate the mechanism behind this explanation, we develop a stylized model of fluctuations with labor market frictions, and investigate how its predictions vary with the parameter that indexes the importance of such frictions.

The main intuition behind that mechanism is easy to describe. The idea goes back to a literature, starting with Oi (1962) and Solow (1964), which attributes the procyclicality of productivity to variations in effort, resulting in seemingly increasing returns to labor. ${ }^{4}$ Suppose that firms have two margins for adjusting their effective labor input: (observed) employment and (unobserved) effort, which we respectively denote (in logs) by $n_{t}$ and

\footnotetext{
${ }^{1}$ As far as we know, Stiroh (2009) was the first to provide evidence of a decline in the labor productivity-hours correlation. Gordon (2010), Barnichon (2008), Galí; and Gambetti (2009), and Nucci and Riggi (2009), using different approaches, independently investigated the potential sources of that decline.

${ }^{2}$ To the best of our knowledge, Galí; and Gambetti (2009) were the first to uncover that finding, but did not provide the kind of detailed statistical analysis found below. Independently, Hall (2007) offered some evidence on the size of the decline in employment in the most recent recessions that is consistent with our finding.

${ }^{3}$ As far as we know, this finding was not known previously, although it is reported in independent work by Gourio (2007) and Champagne and Kurmann (2010).

${ }^{4}$ Contributions include studies by Fair (1969), Fay and Medoff (1985), Hall (1988), Rotemberg and Summers (1990), Bernanke and Parkinson (1991), Shapiro (1993), Burnside, Eichenbaum, and Rebelo (1993), Bils and Cho (1994), Uhlig and Xu (1996), Basu (1996), Basu and Fernald (1997), Basu and Kimball (1997), Shea (1999), Gordon (2004), Wen (2004), Arias, Hansen, and Ohanian (2007), and Gordon (2010)
} 
$e_{t}{ }^{5}$ Labor input (employment and effort) are transformed into output according to a standard production function,

$$
y_{t}=(1-\alpha)\left(n_{t}+\psi e_{t}\right)+a_{t}
$$

where $a_{t}$ is $\log$ total factor productivity and $\alpha$ is a parameter measuring diminishing returns to labor.

Measured labor productivity, or output per person, is given by

$$
y_{t}-n_{t}=-\alpha n_{t}+(1-\alpha) \psi e_{t}+a_{t}
$$

Labor market frictions make it costly to adjust employment $n_{t}$. Effort $e_{t}$ provides an alternative margin of adjustment of labor input and is not subject to those frictions (or to a lesser degree). Thus, the larger the frictions, the less employment fluctuates and the more volatile fluctuations in effort. As a result, a reduction in frictions decreases the volatility of effort and therefore increases the relative volatility of employment with respect to output. The increased volatility of $n_{t}$ also makes labor productivity less procyclical, and, in the presence of shocks other than shifts in technology, may even make productivity countercyclical, consistent with the evidence reported below.

In addition, as emphasized by Hall (2005), the presence of labor market frictions generates a non-degenerate bargaining set for the wage, i.e. a wedge between firms' and workers' reservation wages. Any wage within that bargaining set is consistent with labor market equilibrium. That feature makes room for wage rigidities. We model wages as rigid within the bargaining set, adjusting only when approaching its bounds. In our model, a reduction in labor market frictions narrows the bargaining set and therefore endogenously makes wages more sensitive to shocks, increasing the volatility of fluctuations in wages. If the rigidity is extended to the wages of newly hired workers, then the increased flexibility of wages may dampen the volatility of output and employment in response to shocks. ${ }^{6}$ That feature may help explain the observed decline in the volatility of those two variables in the recent US experience. ${ }^{7}$ Other authors have also argued that the Great Moderation may have been driven at least in part by increased wage flexibility (Gourio (2007), Champagne and Kurmann (2010), Nucci and Riggi (2009)). However, this paper is the first to show that such an increase in wage flexibility can arise endogenously from a decrease in labor market frictions. ${ }^{8}$

\footnotetext{
${ }^{5}$ To simplify the argument, we assume hours per worker are constant, consistent with the observation that in the U.S. data most adjustments in total hours worked take place along the extensive margin.

${ }^{6}$ This is clearly true for technology shocks. As argued in Blanchard and Galí (2008), increased wage flexibility may also dampen the sensitivity of GDP and inflation to oil price shocks.

${ }^{7} \mathrm{~A}$ more flexible labor market does of course not make the economy immune to very large shocks like the recent financial crisis. Under our hypothesis, if the labor market were as rigid as it was in the early 80 s, the current recession might have been even substantially more severe.

${ }^{8}$ Uren (2008) develops a model, in which a reduction in search frictions decreases output volatility. However, the mechanism in that paper (increased assortative matching) is completely different.
} 
The remainder of the paper is organized as follows. Section 2 documents the changes in the patterns of fluctuations in labor productivity, employment and wages. Section 3 develops the basic model. Section 4 describes the outcome of simulations of a calibrated version of the model, and discusses its consistency with the evidence. Section 5 concludes.

\section{Changes in Labor Market Dynamics}

We document three stylized facts regarding postwar changes in US economic fluctuations that motivate our investigation. All three facts are about changes in the dynamics of the labor market and pertain to the cyclical behavior of labor productivity, labor input and wages. We use quarterly time series over the period 1948:1-2007:4 drawn from different sources (see below for a detailed description). To illustrate the changes in the different statistics considered, we split the sample period into two subperiods, pre-84 (1948:1-1983:4) and post-84 (1984:1-2007:4). The choice of the break date is motivated by existing evidence on the timing of the Great Moderation, the sharp drop in output volatility around 1984 (McConell and Pérez-Quirós (2000)).

Our evidence makes use of alternative measures of output and labor input. In all cases labor productivity is constructed as the ratio between the corresponding output and labor input measures. Most of the evidence uses output and hours in the private sector from the BLS Labor Productivity and Cost (LPC) program. We also use GDP as an economy-wide measure of output, with the corresponding labor input measures being total hours or employment. The time series for economy-wide hours is an unpublished series constructed by the BLS and used in Francis and Ramey (2008). The employment series is the usual one from the Current Employment Statistics (CES) establishment survey. In all cases we normalize the output and labor input measures by the size of the civilian noninstitutional population (16 years and older).

We apply two alternative transformations on the logarithms of all variables in order to render the original time series stationary. Our preferred transformation uses the bandpass (BP) filter to remove fluctuations with periodicities below 6 and above 32 quarters, as in Stock and Watson (1999). We also apply the fourth-difference (4D) operator, which is the transformation favored by Stock and Watson (2002) in their analysis of changes in output volatility. ${ }^{9}$

\subsection{The Vanishing Procyclicality of Labor Productivity}

Figure 1 shows the fluctuations at business cycle frequencies in labor productivity in the US over the postwar period. It is clear from the graph that in the earlier part

\footnotetext{
${ }^{9}$ We also showed the results are robust to detrending with the Hodrick-Prescott (HP) filter and to using shorter sample periods, centered around the break date 1984. These estimates, which are suppressed for brevity, are available upon request.
} 
of the sample, productivity was significantly below trend in each recession. However, in the post- 84 data, this is no longer the case. When we calculate the correlation of productivity with output or employment, as in Figure 2, it is clear that there is a sharp drop in the cyclicality of productivity around 1984. The correlation of productivity with output, which used to be strongly positive, fell to a level close to zero, while the correlation of productivity with employment, which was zero or slightly positive in the earlier period of the sample, became negative.

These findings are formalized in Table 1, which reports the contemporaneous correlation between labor productivity and output and employment, for alternative transformations and time periods. In each case, we report the estimated correlation for the pre and post- 84 subsamples, as well as the difference between those estimates. The standard errors, reported in brackets, are computed using the delta method. ${ }^{10}$ We now turn to a short discussion of the results in this Table.

\subsubsection{Correlation with Output}

Independently of the detrending procedure, the correlation of output per hour with output in the pre-84 period is high and significantly positive, with a point estimate around 0.60. In other words, from the vantage point of the early $80 \mathrm{~s}$-the period when the seminal contributions to RBC theory were written- the procyclicality of labor productivity was a well established empirical fact, which lent support to business cycle theories that assigned a central role to technology shocks as a source of fluctuations.

In the post-84 period, however, that pattern changed considerably. The estimates of the productivity-output correlation dropped to a value close to (and not significantly different from) zero. The difference with the corresponding pre- 84 estimates is highly significant. Thus, on the basis of those estimates labor productivity has become an acyclical variable (with respect to output) over the past two decades.

When we use an employment-based measure of labor productivity, output per worker, the estimated correlations also drop substantially but remain significantly greater than zero in the post-84 period. This should not be surprising given that hours per worker are highly procyclical in both subperiods and that their volatility relative to employmentbased labor productivity has increased considerably. ${ }^{11}$

\footnotetext{
${ }^{10}$ We use least squares (GMM) to estimate the second moments (variances and and covariances) of each pair of variables, as well as the (asymptotic) variance-covariance matrix of this estimator. Then, we calculate the standard errors for the standard deviations, the relative standard deviations and the correlation coefficient using the delta method.

${ }^{11}$ Letting $n$ and $h$ denote employment and total hours respectively, a straightforward algebraic manipulation yields the identity:

$$
\rho(y-n, y)=\frac{\sigma_{y-h}}{\sigma_{y-n}} \rho(y-h, y)+\frac{\sigma_{h-n}}{\sigma_{y-n}} \rho(h-n, y)
$$

Thus, even in the case of acyclical hours-based labor productivity, i.e. $\rho(y-h, y) \simeq 0$, we would expect $\rho(y-n, y)$ to remain positive if hours per worker are procyclical, i.e. $\rho(h-n, y)>0$.
} 


\subsubsection{Correlation with Labor Input}

The right-hand side panels in Table 1 display several estimates of the correlation between labor productivity and labor input. The estimates for the pre- 84 period are low, and in the case of output per hour, insignificantly different from zero. Thus, labor productivity was largely acyclical with respect to labor input in that subperiod. This near-zero correlation is consistent with the evidence reported in the early RBC literature, using data up to the mid 80 s. ${ }^{12}$

As was the case when using output as the cyclical indicator, the estimated correlations between labor productivity and employment decline dramatically in the post-84 period. In fact these correlations become significantly negative for output per hour, with a point estimate ranging from -0.40 to -0.54 , depending on the filter. The change with respect to the pre-84 period is highly significant. In other words, labor productivity in the past two decades has become strongly countercyclical with respect to labor input.

\subsection{The Rising Relative Volatility of Labor Input}

The left-hand panel of Table 2 displays the standard deviation of several measures of labor input in the pre and post-84 periods, as well as the ratio between the two. The variables considered include employment in the private sector, hours in the private sector (employment times hours per worker) and economy-wide hours. The decline in the volatility of hours since the mid 80 s, like that of other major macro variables, is seen to be large and highly significant, with the standard deviation falling between $35 \%$ and $49 \%$ and always significantly so.

A more interesting piece of evidence is the change in the relative volatility of labor input, measured as the ratio of the standard deviation of labor input to the standard deviation of output. These estimates are presented in the right-hand panel of Table 2. Without exception, all labor input measures have experienced an increase in their relative volatility in the post versus pre- 84 period. In other words, the decline in the variability of labor input has been less pronounced than that of output. The increase in the relative volatility of hours worked ranges from $30 \%$ to $48 \%$ in the private sector and from $7 \%$ to $30 \%$ in the total economy. The corresponding increase for employment is slightly smaller, ranging from $23 \%$ to $43 \%$ in the private sector, but is still statistically significant.

The previous evidence points to a rise in the elasticity of labor input with respect to output. Put differently, firms appear to have relied increasingly on labor input adjustments in order to meet their changes in output.

\footnotetext{
${ }^{12}$ Christiano and Eichenbaum (1992) used data up to 1983:4 (which coincides with the cut-off date for our first subperiod), but starting in 1955:4. Their estimates of the correlation between labor productivity and hours were -0.20 when using household data and 0.16 using establishment data.
} 


\subsection{The Rising Volatility of Wages}

Next we turn our attention to the volatility of (real) wages, both in absolute and relative terms. We consider four different wage measures. The first three are constructed as real compensation per hour. The first difference is in the measure of compensation, which is measured either from the national income and product accounts (NIPA) or as earnings from the CES establishment survey. The second difference is in the measure of hours, which refers to the private sector or to the total economy. ${ }^{13}$ The fourth measure is usual hourly earnings (or usual weekly earnings divided by usual weekly hours) from the Current Population Statistics (CPS). For all measures, compensation or earnings are deflated using the compensation deflator from the LPC, but the results are robust to deflating with the consumer price index (CPI-U) as we show below.

\subsubsection{Average Wages}

The left-hand panel of Table 3 displays the standard deviation for each wage measure for different detrending procedures. Our statistics uncover a surprising finding: despite the general decline in macro volatility associated with the Great Moderation, the volatility of several wage measures has increased in absolute terms. The estimated increase the standard deviation is fairly large, between 10 and $42 \%$ and mostly significant for the bandpass filtered NIPA-based wage measures. Using fourth differences, the increase is much smaller and no longer significant and by some periods there seems to have been a (small) decrease in wage volatility.

Using earnings per hour from the CES, however, there seems to be a large and highly significant reduction in wage volatility. ${ }^{14}$ One difference between the two measures is that the NIPA compensation measure includes non-wage payments and, in particular, employee stock options. Mehran and Tracy (2001) have argued that since these options are recorded when they realize rather than when they are handed out to employees, the NIPA measure gives a misleading picture of the evolution and volatility of compensation in the 90s. However, using the CPS measure of usual hourly earnings, presented in Table 4, which includes non-wage compensation but not stock options, we again observe a fairly large increase in the volatility of wages. ${ }^{15}$ Given the short time series available

\footnotetext{
${ }^{13}$ Our baseline measure uses compensation from the NIPA and hours in the private sector and corresponds to compensation per hour from the BLS labor productivity and cost program (LPC).

${ }^{14}$ This finding is not driven by the fact that the CES earnings measure is only available after 1965. If we restrict the sample for the NIPA based wage measures to the 1965-2004, the volatility statistics for these measures look very similar those in the table.

${ }^{15}$ We use data from the CPS outgoing rotation groups. Since these data are available only from 1979 onwards, we compare the volatility over the 1980-1984 period (allowing for fourth differences) with that of the 1985-2005 period. For comparison, the first panel of Table 4 presents the volatility of our baseline measure for compensation per hour for this period. The second panel presents comparable statistics from the CPS series. Because the CPS wage series is based on a fairly small cross-section of workers, there is substantial measurement error in these series. Therefore, the standard deviations of the fourth differenced data are biased upward, see Haefke, Sonntag, and van Rens (2008) for details.
} 
for these data, it is remarkable that the increase in volatility is (borderline) significant for the bandpass filtered series. Using fourth differences, wage volatility seems roughly constant.

Our finding that wage volatility increased or at least did not decrease around the time of the Great Moderation, although with a caveat, is consistent with the results in Champagne and Kurmann (2010), who also use the CPS to show that the increase in wage volatility is not driven by compositional changes in the labor force. To the best of our knowledge, this result was not previously known. ${ }^{16}$

An immediate implication of the previous finding, and the one that we want to emphasize here, is the possibly very large increase in the relative volatility of wages with respect to to output or labor input, as shown in the right-hand panels of Tables 3 and 4 . The relative volatility of wages with respect to output more than doubled for the NIPA-based measures and for the CPS wage. We interpret this evidence as being consistent with a decline in the significance of real wage rigidities around $1984 .{ }^{17}$

\subsubsection{Wages of Newly Hired Workers}

On a frictional labor market, the average wage is not allocative, since the frictions drive a wedge between the reservation wages of firms and workers. Therefore, in order to assess the implications of increased wage flexibility for other labor market variables, we also consider the volatility of the wage of newly hired workers as suggested by Haefke, Sonntag, and van Rens (2008) and Pissarides (2009).

Table 4 presents volatility statistics for the wage of new hires, constructed from the CPS as in Haefke, Sonntag, and van Rens (2008). ${ }^{18}$ The first thing to notice is that the wage of newly hired workers is much more volatile than the average wage in the entire labor force. This is consistent with the results in Haefke, Sonntag, and van Rens (2008), who argue that, in the post-84 period, wages of newly hired workers are perfectly flexible, in the sense that they respond one-to-one to changes in labor productivity. Here, we focus on the change in the volatility of wages over time.

The absolute volatility of the wage of newly hired workers, unlike the average wage, decreased substantially and significantly between the pre and post-84 periods. As a result, the increase in the relative volatility with respect to output is much smaller for

There is no reason however, why the ratio of the standard deviations before and after 1984 would be biased. In addition, the bandpass filtered data, which do not include the high frequencies induced by the measurement error, are not subject to this bias.

${ }^{16}$ Stock and Watson (2002) uncover breaks in the volatility of a long list of macro variables, but they do not provide evidence for any wage measure.

${ }^{17}$ Blanchard and Galí (2008) argue that a reduction in the rigidity of real wages is needed in order to account for the simultaneous decline in inflation and output volatility, in the face of oil price shocks of a similar magnitude.

${ }^{18}$ But unlike in that paper, we do not correct fluctuations in the CPS wage series for changes in the composition of the labor force by demographic characteristics, education level and experience for comparability with the other wage measures. Doing so however, makes very little difference for the conclusions presented here. 
new hires, ranging between $3 \%$ and $69 \%$, depending on whether we use the mean or median wage and on the filter used. Although the increase in the relative volatility of the wage of newly hired workers is much less pronounced, there is some evidence that wages fluctuated more between recessions and booms also for this group of workers. This finding is consistent with the evidence presented in Haefke, Sonntag, and van Rens (2008, section 3.4) and points towards a decrease in wage rigidity that may be important for employment fluctuations.

\subsection{Conclusions}

Summarizing, we showed that labor productivity became less procyclical or acyclical with respect to output, and countercyclical with respect to employment. In addition, the relative volatility of both employment and wages increased. For completeness, we also report that the relative volatility of labor productivity increased, and the correlation between employment and output decreased slightly, see Table $5 .{ }^{19}$ These changes coincided with the reduction in volatility in output and most other macroeconomic aggregates, the so called Great Moderation. This evidence is suggestive of structural change in the labor market.

In macroeconomic models with a perfectly competitive labor market and a standard production function, wages are proportional to labor productivity. ${ }^{20}$ Our evidence makes clear that the extent to which this is true in the data depends very much on the period one looks at. From Tables 3 and 5, we see that the relative standard deviation of wages with respect to labor productivity was about $0.3-0.7$ in the the pre- 84 period. In the post-84 period, this relative standard deviation more than doubled to about $1.2-1.3$. This is consistent with the evidence in Haefke, Sonntag, and van Rens (2008, section 3.4), who show that the elasticity of wages with respect to productivity in 1984 increases from 0.2 to 0.4 for all workers, and from 0.3 to 0.8 for newly hired workers. This evidence suggests that labor market frictions are crucial to understand the observed changes in labor market dynamics.

In the remainder of this paper, we will show that the vanishing procyclicality of labor productivity and the increasing relative volatility of employment, can be explained by a reduction in labor market frictions, if production requires an unobservable input, e.g. effort. If wages are set competitively, then a reduction in labor market frictions, which makes employment faster to adjust, should make wages relatively less volatile. Although the relative standard deviation of wages decreased in some datasets, we argued above that the majority of the evidence seems to point towards a large increase in the relative

\footnotetext{
${ }^{19}$ These observations are completely determined by the statistics already reported and do not contain independent information We emphasize the statistics that we considered easiest to interpret.

${ }^{20}$ With competitive labor markets, the wage equals the marginal product of labor, and with a CobbDouglas production function, the marginal and average product of labor are proportional to eachother. This well-known argument, which does not rely on business cycles being driven by productivity shocks, was used recently by Rogerson and Shimer (2010, section 1.3.2).
} 
volatility of wages. Therefore, we show below how the model can be extended with endogenous wage rigidities in order to generate this result.

\section{A Model of Fluctuations with Labor Market Frictions and Endogenous Effort}

Having documented in some detail the changing patterns of labor productivity, labor input, and wages, we turn to possible explanations. More specifically, and as anticipated in the introduction, we explore the hypothesis that all three observed changes documented above may have, at least partly, been caused by the same institutional change: increasing flexibility of the labor market.

To formalize this explanation, we develop a model of fluctuations with labor market frictions, modelled as adjustment costs in employment (hiring costs). The crucial element in this model is an endogenous effort choice, which provides an intensive margin for labor adjustment that is not subject to the adjustment costs. Since the purpose of the model is to illustrate the main mechanisms at work, we keep the model as simple as possible in dimensions that are likely to be orthogonal to the factors emphasized by our analysis. Thus, we abstract from endogenous capital accumulation, trade in goods and assets with the rest of the world, and imperfections in the goods and financial markets. We also ignore any kind of monetary frictions, even though we recognize that these, in conjunction with changes in the conduct of monetary policy in the VolckerGreenspan years, may have played an important role in accounting for the decline in macro volatility. ${ }^{21}$

\subsection{Households}

Households are infinitely-lived and consist of a continuum of identical members represented by the unit interval. The household is the relevant decision unit for choices about consumption and labor supply. Each household member's utility function is additively separable in consumption and leisure, and the household assigns equal consumption $C_{t}$ to all members in order to share consumption risk within the household. Thus, the household's objective function is given by,

$$
E_{0} \sum_{t=0}^{\infty} \beta^{t}\left[\frac{Z_{t} C_{t}^{1-\eta}}{1-\eta}-\gamma L_{t}\right]
$$

where $\beta \in(0,1)$ is the discount factor, $\eta \in[0,1]$ is the inverse of the intertemporal elasticity of substitution, $\gamma>0$ can be interpreted as a fixed cost of working and $Z_{t}$ is a preference shock. The second term in the period utility function is disutility from

\footnotetext{
${ }^{21}$ See, e.g. Clarida, Galí, and Gertler (2000) for a discussion of the possible role of monetary policy in the Great Moderation.
} 
effective labor supply $L_{t}$, which depends on the fraction $N_{t}$ of household members that are employed, as well as on the amount of effort $\mathcal{E}_{i t}$ exerted by each employed household member $i$. Formally,

$$
L_{t}=\int_{0}^{N_{t}} \frac{1+\zeta \mathcal{E}_{i t}^{1+\phi}}{1+\zeta} d i=\frac{1+\zeta \mathcal{E}_{t}^{1+\phi}}{1+\zeta} N_{t}
$$

where the second equality imposes the equilibrium condition that all working household members exert the same level of effort, $\mathcal{E}_{i t}=\mathcal{E}_{t}$ for all $i$. The parameter $\zeta \geq 0$ measures the importance of effort for the disutility of working, and the elasticity parameter $\phi \geq 0$ determines the degree of increasing marginal disutility from exerting effort. For simplicity we assume a constant workweek, thus restricting the intensive margin of labor input adjustment to changes in effort.

The household maximizes its objective function above subject to the sequence of budget constraints,

$$
C_{t}=\int_{0}^{N_{t}} W_{i t} d i+\Pi_{t}
$$

where $\Pi_{t}$ represents firms' profits, which are paid out to households in the form of lump-sum dividents, and $W_{i t}$ are wages accruing to employed household member $i$. The household takes into account the effect of its decisions on the level of effort exerted by its members.

\section{$3.2 \quad$ Firms}

Firms produce a homogenous consumption good using a production technology that uses labor and effort as inputs,

$$
Y_{t}=A_{t}\left(\int_{0}^{N_{t}} \mathcal{E}_{i t}^{\psi} d i\right)^{1-\alpha}=A_{t}\left(\mathcal{E}_{t}^{\psi} N_{t}\right)^{1-\alpha}
$$

where $Y_{t}$ is output, $\mathcal{E}_{i t}$ is effort exerted by worker $i, \alpha \in(0,1)$ is a parameter that measures diminishing returns to total labor input in production, $\psi \in[0,1]$ measures additional diminishing returns to effort, and $A_{t}$ is a technology shock common to all firms. Since all firms are identical, we normalize the number of firms to the unit interval, so that $Y_{t}$ and $N_{t}$ denote output and employment of each firm as well as aggregate output and employment in the economy. The second equality imposes the equilibrium condition that all workers in a firm exert the same level of effort, $\mathcal{E}_{i t}=\mathcal{E}_{t}$ for all $i$.

Firms choose how many workers to hire $H_{t}$ in order to maximize the expected discounted value of profits,

$$
E_{0} \sum_{t=0}^{\infty} Q_{0, t}\left[Y_{t}-W_{t} N_{t}-g\left(H_{t}\right)\right]
$$


subject to a law of motion for employment implied by the labor market frictions,

$$
N_{t}=(1-\delta) N_{t-1}+H_{t}
$$

where the function $g($.$) , with g^{\prime}>0$ and $g^{\prime \prime}>0$, represents the costs (in terms of output) of hiring new workers and $Q_{0, t}$ is the stochastic discount factor for future profits. The stochastic discount factor is defined recursively as $Q_{0, t} \equiv Q_{0,1} Q_{1,2} \ldots Q_{t-1, t}$, where

$$
Q_{t, t+1} \equiv \beta \frac{Z_{t+1}}{Z_{t}}\left(\frac{C_{t}}{C_{t+1}}\right)^{\eta}
$$

measures the marginal rate of substitution between two subsequent periods. Like the household, the firm takes into account the effect of its decisions on the level of effort exerted by its workers.

\subsection{Effort Choice and Job Creation}

The household and the firm jointly decide the wage and the level of effort that the worker will put into the job. In equilibrium, the effort level of all workers is set efficiently, maximizing the total surplus generated by each match. ${ }^{22}$ This efficient effort level, in each period and for each worker, equates the cost of exerting more effort, higher disutility to the household, to the benefit, higher production and therefore profits for the firm.

Consider a worker $i$, who is a member of household $h$ and is employed in firm $j$. The marginal disutility to the household from that worker exerting more effort, expressed in terms of consumption, is obtained from equation (2) for total effective labor supply and equals:

$$
\frac{\gamma C_{h t}^{\eta}}{Z_{t}} \frac{\partial L_{h t}}{\partial \mathcal{E}_{i t}}=\frac{(1+\phi) \zeta}{1+\zeta} \frac{\gamma C_{h t}^{\eta} \mathcal{E}_{i t}^{\phi}}{Z_{t}} d i
$$

The marginal product of that additional effort to the firm is found from production function (4):

$$
\frac{\partial Y_{j t}}{\partial \mathcal{E}_{i t}}=(1-\alpha) \psi A_{t}\left(\int_{0}^{N_{j t}} \mathcal{E}_{v t}^{\psi} d v\right)^{-\alpha} \mathcal{E}_{i t}^{-(1-\psi)} d i
$$

In equilibrium, the marginal disutility from effort must equal its marginal product for all workers $i$. Also, because all firms and all households are identical, it must be that $C_{h t}=C_{t}$ and $N_{j t}=N_{t}$ in equilibrium. Therefore, it follows that all workers exert the same level of effort in equilibrium, $\mathcal{E}_{i t}=\mathcal{E}_{t}$ for all $i$. Imposing this property, we obtain the following equilibrium condition for effort,

$$
\mathcal{E}_{t}=\left[\frac{(1-\alpha) \psi(1+\zeta)}{(1+\phi) \zeta} \frac{Z_{t}}{\gamma C_{t}^{\eta}} A_{t} N_{t}^{-\alpha}\right]^{\frac{1}{1+\phi-(1-\alpha) \psi}}
$$

\footnotetext{
${ }^{22}$ Suppose not. Then, household and firm could agree on a different effort level that increases total match surplus, and a modified surplus sharing rule (wage) that would make both parties better off.
} 
or, using production function (4) to simplify:

$$
\mathcal{E}_{t}^{1+\phi}=\frac{\psi}{1+\phi} \frac{1+\zeta}{\zeta} \frac{Z_{t}}{\gamma C_{t}^{\eta}} \frac{(1-\alpha) Y_{t}}{N_{t}}
$$

When considering whether to hire a worker, firms take into account the impact of the resulting increase in employment on the effort level exerted by their workers. Thus, the marginal product of a new hire is given by, ${ }^{23}$

$$
\frac{d Y_{j t}}{d N_{j t}}=\frac{\partial Y_{j t}}{\partial N_{j t}}+\frac{\partial Y_{j t}}{\partial \mathcal{E}_{j t}} \frac{\partial \mathcal{E}_{j t}}{\partial N_{j t}}=\left(1-\Psi_{F}\right) \frac{(1-\alpha) Y_{t}}{N_{t}}
$$

where $\Psi_{F}=\frac{\alpha \psi}{1+\phi-(1-\alpha) \psi}$ measures the additional (negative) effect from a new hire on output that comes from the endogenous response of the effort level in the firm.

Maximizing the expected net present value of profits (5), where output is given by production function (4) and the stochastic discount factor by (7), subject to the law of motion for employment implied by the matching technology (6) and the equilibrium condition for effort (11), gives rise to the following first order condition,

$$
g^{\prime}\left(H_{t}\right)=S_{t}^{F}
$$

where $S_{t}^{F}$ is the marginal value to the firm of having an additional worker in period $t$, which is given by,

$$
\begin{aligned}
S_{t}^{F} & =\left(1-\Psi_{F}\right) \frac{(1-\alpha) Y_{t}}{N_{t}}-W_{t}+(1-\delta) E_{t}\left[Q_{t, t+1} S_{t+1}^{F}\right] \\
& =E_{t} \sum_{s=0}^{\infty}(1-\delta)^{s} Q_{t, t+s}\left[\left(1-\Psi_{F}\right) \frac{(1-\alpha) Y_{t+s}}{N_{t+s}}-W_{t+s}\right]
\end{aligned}
$$

where the second equality follows from iterating forward (and defining $Q_{t, t}=1$ ). This is a job creation equation, which states that the marginal costs of hiring a new worker $g^{\prime}\left(H_{t}\right)$, must equal the expected net present value of marginal profits (additional output minus the wage) of the filled job, $S_{t}^{F}$.

\subsection{The Bargaining Set}

Because of labor market frictions, employment relationships generate a strictly positive surplus. The reason is that if firm and worker cannot agree to continue their relationship,

\footnotetext{
${ }^{23}$ With a slight abuse of notation, $\mathcal{E}_{j t}$ denotes the effort level exerted by all workers (from different households) in a particular firm $j$. Firm $j$ considers employing $N_{j t}$ workers, given that all other firms employ the equilibrium number of workers $N_{t}$. Because there are infinitely many firms, firm $j$ 's decision to employ $N_{j t} \neq N_{t}$ workers does not affect the fraction of household $h$ 's members that are employed, so that by the assumption of perfect risk-sharing within the household, the consumption of workers in firm $j, C_{h t}=C_{t}$, is not affected. Therefore, the relation between effort and employment that the firm faces if all other firms (and all households) play equilibrium strategies, is given by equation (10), keeping $C_{t}$ fixed. See appendix A for details on the derivation of equation (12).
} 
then the firm has to pay the hiring costs again in order to find another worker to match with. Firms and households bargain over the wage as a way to share the match surplus. These negotations are limited only by the outside option of each party. The lower bound of the bargaining set is given by the reservation wage of the household, the wage offer at which the household is indifferent between accepting the offer and looking for another job. Similarly, the upper bound of the bargaining set is the reservation wage of the firm, the wage offer that makes the firm indifferent between accepting the offer and hiring a different worker. Within these bounds, any wage is consistent with equilibrium, see Hall (2005). Clearly, the bounds of the bargaining set are endogenous variables, which we now derive before introducing an equilibrium selection rule for the wage within the bargaining set.

The part of the match surplus that accrues to the firm $S_{t}^{F}$, as a function of the wage, is given by equation (14). In order to derive a similar expression for the household's part of the surplus $S_{t}^{H}$, we must first calculate the marginal disutility to the household of having one additional employed member, taking into account the endogenous response of effort. This marginal disutility of employment, expressed in terms of consumption, is given by, ${ }^{24}$

$$
\frac{\gamma C_{t}^{\eta}}{Z_{t}} \frac{d L_{h t}}{d N_{h t}}=\frac{1}{1+\zeta} \frac{\gamma C_{t}^{\eta}}{Z_{t}}\left(1+\zeta \frac{(1+\phi) \Psi_{H}}{\psi} \mathcal{E}_{t}^{1+\phi}\right)=\frac{1}{1+\zeta} \frac{\gamma C_{t}^{\eta}}{Z_{t}}+\Psi_{H} \frac{(1-\alpha) Y_{t}}{N_{t}}
$$

where the second equality follows from substituting equation (11), and where $\Psi_{H}=$ $\frac{\psi}{1+\phi} \frac{(1-\eta)(1+\phi)-\psi}{1+\phi-\psi}$ captures the effect on utility of one more employed member in the household through the endogenous response of effort. Using this expression, we can take a derivative of the household's objective function (1) with respect to $N_{t}$ and divide by the marginal utility of consumption, to obtain the following expression for $S_{t}^{H}$.

$$
S_{t}^{H}=W_{t}-\frac{1}{1+\zeta} \frac{\gamma C_{t}^{\eta}}{Z_{t}}-\Psi_{H} \frac{(1-\alpha) Y_{t}}{N_{t}}+(1-\delta) E_{t}\left[Q_{t, t+1} S_{t+1}^{H}\right]
$$

The value to the household of having one more employed worker, equals the wage minus the disutility expressed in terms of consumption, plus the expected value of still having that worker next period, which is discounted by the probability that the worker is still employed next period.

The upper bound of the bargaining set $W_{t}^{U B}$ is the highest wage such that $S_{t}^{F} \geq 0$, whereas the lower bound $W_{t}^{L B}$ is the lowest wage such that $S_{t}^{H} \geq 0$. Using equations (14) and (17), we get $S_{t}^{F}=W_{t}^{U B}-W_{t}$ and $S_{t}^{H}=W_{t}-W_{t}^{L B}$. Substituting back into equations (13), (14) and (17), we can explicitly write the equilibrium of the model in terms of the wage and the bounds of the bargaining set.

$$
g^{\prime}\left(H_{t}\right)=W_{t}^{U B}-W_{t}
$$

\footnotetext{
${ }^{24}$ The derivation of this expression is similar to that of equation (12), see appendix A for details.
} 


$$
\begin{gathered}
W_{t}^{U B}=\left(1-\Psi_{F}\right) \frac{(1-\alpha) Y_{t}}{N_{t}}+(1-\delta) E_{t}\left[Q_{t, t+1}\left(W_{t+1}^{U B}-W_{t+1}\right)\right] \\
W_{t}^{L B}=\frac{1}{1+\zeta} \frac{\gamma C_{t}^{\eta}}{Z_{t}}+\Psi_{H} \frac{(1-\alpha) Y_{t}}{N_{t}}+(1-\delta) E_{t}\left[Q_{t, t+1}\left(W_{t+1}^{L B}-W_{t+1}\right)\right]
\end{gathered}
$$

Everything else equal, the more rigid is the wage in response to technology or preference shocks that shift the bounds of the bargaining set, the more volatile is hiring $H_{t}$ and therefore employment $N_{t}$ in response to those shocks, see equation (18). We now turn to various possibilities for how wages are determined within the bargaining set.

\subsection{Wage Determination}

One possible criterion for wage determination that we can interpret as flexible wages in a model with a frictional labor market, is period-by-period Nash bargaining. Nash bargaining assumes that the wage is set such that the total surplus from the match is split in equal proportions between household and firm. It is straightforward to see that in our framework, this assumption implies that the wage is the average of the lower and upper bounds of the bargaining set, $S_{t}^{H}=\frac{1}{2}\left(S_{t}^{H}+S_{t}^{F}\right)=\frac{1}{2}\left(W_{t}^{U B}-W_{t}^{L B}\right)$. Then,

$$
W_{t}^{*}=\frac{1}{2}\left(W_{t}^{U B}+W_{t}^{L B}\right)
$$

where $W_{t}^{*}$ denotes the Nash bargained wage.

Shimer (2005) and Hall (2005), among others, have argued that period-by-period Nash bargaining generates too volatile a wage in equilibrium, relative to what is observed in the data. As discussed below, in our model period-by-period Nash bargaining leads to fluctuations in the (log) wage of the same amplitude as labor productivity, and perfectly correlated with the latter. This is at odds with the data, where wages are about half as volatile as labor productivity in the pre- 84 period, with the correlation between the two variables much smaller than one. Both the relative volatility of wages and their correlation with labor productivity increases significantly in the post-84 period. This motivates the introduction of a wage setting mechanism that departs from period-byperiod Nash bargaining. ${ }^{25}$ We use the following wage determination process,

$$
W_{t}=R_{t-1} W_{t-1}+\left(1-R_{t-1}\right) W_{t}^{*}
$$

where $R_{t}$ measures the degree of wage rigidity, which is endogenous.

Only wages within the bargaining set are renegotiation-proof and therefore consistent with equilibrium, see Barro (1977). The maximum degree of wage stickiness that respects this condition, is for the wage to remain fixed inside the bargaining set, but to be adjusted

\footnotetext{
${ }^{25}$ This is consistent with the recent trend in the literature, see e.g. Hall (2005), Blanchard and Galí (2007), Hall and Milgrom (2008), Christoffel and Kuester (2008), Gertler and Trigari (2009), and Shimer (2009).
} 
when it hits either bound. This is the wage determination mechanism in Thomas and Worrall (1988) and Hall (2003). We use a convex version of this wage rule, in order to be able to solve the model using perturbation methods, and assume the following reduced-form equation for wage rigidity,

$$
R_{t}=\bar{R}\left(1-\left(\frac{W_{t}-W_{t}^{*}}{\frac{1}{2}\left(W_{t}^{U B}-W_{t}^{L B}\right)}\right)^{2 \rho}\right)
$$

where $\rho \in \mathbb{N}_{0}^{+}$. This wage rule captures the idea that the wage is more likely to adjust when it is closer to the bounds of the bargaining set. The parameter $\rho$ captures the degree of non-linearity in this relation. For $\rho=0, R_{t}=0$ and $W_{t}=W_{t}^{*}$, i.e. wages are flexible. For $\rho \in \mathbb{N}^{+}$, the degree of wage rigidity is endogenous, with wages being perfectly flexible at the upper or lower bound of the bargaining set and most rigid at the Nash-bargained wage $W_{t}^{*}$. As $\rho$ becomes larger, wages are rigid in a larger part of the bargaining set. The limiting case for $\rho \rightarrow \infty$ and $\bar{R}=1$ captures the case where the wage is fixed within the bargaining set but adjusts when it has to in order to avoid inefficient match destruction as in Hall (2003). We consider a flexible wage regime with $\rho=0$ and regime with endogenous wage rigidity, $\rho \in \mathbb{N}^{+}$and $\bar{R}=1$.

The crucial insight for our purposes is that with this type of wage rule, the degree of wage rigidity depends endogenously on the size of the frictions. If frictions decrease, the width of the bargaining set decreases as well, so that there is less room for wage rigidity. Notice also that this type of wage rigidity can never lead to inefficient match destruction.

\subsection{Equilibrium}

We conclude the description of the model by listing the conditions that characterize the equilibrium. Vacancy posting decisions by firms are summarized by the job creation equation (18).

$$
g^{\prime}\left(H_{t}\right)=W_{t}^{U B}-W_{t}
$$

The equilibrium level of effort is determined by efficiency condition (11),

$$
\mathcal{E}_{t}^{1+\phi}=\frac{\psi}{1+\phi} \frac{1+\zeta}{\zeta} \frac{Z_{t}}{\gamma C_{t}^{\eta}} \frac{(1-\alpha) Y_{t}}{N_{t}}
$$

and wage negotations are described by equations (22) and (23) for the equilibrium selection rule, and stochastic difference equations for the upper and lower bounds of the bargaining set (19) and (20).

$$
W_{t}=R_{t} W_{t-1}+\left(1-R_{t}\right) \frac{1}{2}\left(W_{t}^{U B}+W_{t}^{L B}\right)
$$




$$
\begin{gathered}
R_{t}=\bar{R}\left(1-\left(\frac{W_{t}-\frac{1}{2}\left(W_{t}^{U B}+W_{t}^{L B}\right)}{\frac{1}{2}\left(W_{t}^{U B}-W_{t}^{L B}\right)}\right)^{2 \rho}\right) \\
W_{t}^{U B}=\left(1-\Psi_{F}\right) \frac{(1-\alpha) Y_{t}}{N_{t}}+(1-\delta) E_{t}\left[Q_{t, t+1}\left(W_{t+1}^{U B}-W_{t+1}\right)\right] \\
W_{t}^{L B}=\frac{1}{1+\zeta} \frac{\gamma C_{t}^{\eta}}{Z_{t}}+\Psi_{H} \frac{(1-\alpha) Y_{t}}{N_{t}}+(1-\delta) E_{t}\left[Q_{t, t+1}\left(W_{t+1}^{L B}-W_{t+1}\right)\right]
\end{gathered}
$$

Employment evolves according to its law of motion (6).

$$
N_{t}=(1-\delta) N_{t-1}+H_{t}
$$

Finally, goods market clearing requires that consumption equals output minus hiring costs.

$$
C_{t}=Y_{t}-g\left(H_{t}\right)
$$

Output is defined as in production function (4), and the stochastic discount factor as the marginal rate of intertemporal substitution (7).

$$
\begin{gathered}
Y_{t}=A_{t}\left(\mathcal{E}_{t}^{\psi} N_{t}\right)^{1-\alpha} \\
Q_{t, t+1}=\beta \frac{Z_{t+1}}{Z_{t}}\left(\frac{C_{t}}{C_{t+1}}\right)^{\eta}
\end{gathered}
$$

and the parameters $\Psi_{F}=\frac{\alpha \psi}{1+\phi-(1-\alpha) \psi}$ and $\Psi_{H}=\frac{\psi}{1+\phi} \frac{(1-\eta)(1+\phi)-\psi}{1+\phi-\psi}$ are functions of the structural parameters. In total, we have 8 equations in the endogenous variables $H_{t}$, $\mathcal{E}_{t}, W_{t}, R_{t}, W_{t}^{U B}, W_{t}^{L B}, N_{t}$ and $C_{t}$, or 10 equations including the definitions for $Y_{t}$ and $Q_{t, t+1}$.

Without an endogenous effort choice ( $\psi=0$ so that effort is not useful in production, $\Psi_{F}=\Psi_{H}=0$, and $\mathcal{E}_{t}=0$ for all $t$ in equilibrium), and with flexible wages ( $\bar{R}=0$ so that $R_{t}=0$ for all $t$ ), the model reduces to a standard RBC model with labor market frictions. However, unlike in the standard model, fluctuations in our model are driven by technology shocks as well as non-technology shocks or preference shocks. The two driving forces of fluctuations, $\log$ total factor productivity $a_{t} \equiv \log A_{t}$ and $\log$ preferences over consumption $z_{t} \equiv \log Z_{t}$ follow stationary $A R(1)$ processes,

$$
\begin{aligned}
& a_{t}=\rho_{a} a_{t-1}+\varepsilon_{t}^{a} \\
& z_{t}=\rho_{z} z_{t-1}+\varepsilon_{t}^{z}
\end{aligned}
$$

where $\varepsilon_{t}^{a}$ and $\varepsilon_{t}^{z}$ are independent white noise processes with variances given by $\sigma_{a}^{2}$ and $\sigma_{z}^{2}$ respectively.

We now proceed to use this model to analyze the possible role of labor market 
frictions in generating the observed changes in the cyclical patterns of output, labor input, productivity, and wages. For this analysis, all three above-mentioned elements are important, i.e. multiple shocks, endogenous effort and endogenous wage rigidity.

\section{The Increasing Flexibility of the Labor Market}

This section provides an analysis of our model economy's equilibrium under alternative assumptions regarding the size of labor market frictions and wage determination. We start by looking at a version of the model with a frictionless labor market. This model provides a useful benchmark that we can solve for in closed form. Then, we introduce frictions and rely on numerical methods to simulate the model for different calibrations of the parameters.

\subsection{The Frictionless Case}

Consider the limiting case of an economy without labor market frictions, i.e. $g(H)=0$ for all $H$. The first thing to note is that in this case the width of the bargaining set collapses to zero, and the job creation equation (24) and the wage block of the model, equations (26), (27), (28) and (29), imply

$$
W_{t}=W_{t}^{U B}=W_{t}^{L B}=\left(1-\Psi_{F}\right) \frac{(1-\alpha) Y_{t}}{N_{t}}=\frac{1}{1+\zeta} \frac{\gamma C_{t}^{\eta}}{Z_{t}}+\Psi_{H} \frac{(1-\alpha) Y_{t}}{N_{t}}
$$

for all $t$. Employment becomes a choice variable, so that its law of motion (30) is dropped from the system and employment is instead determined by the static condition (36).

$$
N_{t}=(1-\alpha)\left(1-\Psi_{F}-\Psi_{H}\right) \frac{(1+\zeta) Z_{t} Y_{t}}{\gamma C_{t}^{\eta}}
$$

Substituting into the equilibrium condition for effort (25), we obtain

$$
\mathcal{E}_{t}^{1+\phi}=\frac{\psi}{1+\phi} \frac{1}{\zeta} \frac{1}{1-\Psi_{F}-\Psi_{H}}
$$

implying an effort level that is invariant to fluctuations in the model's driving forces. Since effort has stronger diminishing returns in production and stronger increasing marginal disutility than employment, this intensive margin of adjustment is never used if the extensive margin is not subject to frictions.

Without hiring costs, the aggregate resource constraint (31) reduces to $C_{t}=Y_{t}$. Combining the resource constraint and equations (37) and (38) with the production function (32), we can derive closed-form expressions for equilibrium employment, output, wages and labor productivity. Using lower-case letters to denote the natural logarithms of the original variables, ignoring constant terms and normalizing the variance of the 
shocks, ${ }^{26}$ we get:

$$
\begin{gathered}
n_{t}=(1-\eta) a_{t}+z_{t} \\
y_{t}=a_{t}+(1-\alpha) z_{t} \\
w_{t}=y_{t}-n_{t}=\eta a_{t}-\alpha z_{t}
\end{gathered}
$$

A useful benchmark is the model with logarithmic utility over consumption $(\eta=1)$. In this case, employment fluctuates in proportion to the preference shifter $z_{t}$ but does not respond to technology shocks. ${ }^{27}$

From the previous equations, it is straightforward to calculate the model's implications for the second moments of interest. In particular we have

$$
\begin{aligned}
& \operatorname{cov}\left(y_{t}-n_{t}, y_{t}\right)=\eta \operatorname{var}\left(a_{t}\right)-\alpha(1-\alpha) \operatorname{var}\left(z_{t}\right) \\
& \operatorname{cov}\left(y_{t}-n_{t}, n_{t}\right)=\eta(1-\eta) \operatorname{var}\left(a_{t}\right)-\alpha \operatorname{var}\left(z_{t}\right)
\end{aligned}
$$

In the absence of labor market frictions, labor productivity is unambiguously countercyclical in response to preference shocks. The intuition for this result is that output responds to preference shocks only through employment, and this response is less than proportional because of diminishing returns in labor input $(\alpha>0)$. Since productivity is unambiguously procyclical in response to technology shocks, the unconditional correlations depend on the relative variances of the shocks and the model parameters. For a wide range of parameter values, e.g. with logarithmic utility over consumption $(\eta=1)$, productivity is procyclical with respect to output but countercyclical with respect to employment.

The relative volatility of employment and wages with respect to output are given by the following expressions:

$$
\begin{aligned}
& \frac{\operatorname{var}\left(n_{t}\right)}{\operatorname{var}\left(y_{t}\right)}=\frac{(1-\eta)^{2} \operatorname{var}\left(a_{t}\right)+\operatorname{var}\left(z_{t}\right)}{\operatorname{var}\left(a_{t}\right)+(1-\alpha)^{2} \operatorname{var}\left(z_{t}\right)} \\
& \frac{\operatorname{var}\left(w_{t}\right)}{\operatorname{var}\left(y_{t}\right)}=\frac{\eta^{2} \operatorname{var}\left(a_{t}\right)+\alpha^{2} \operatorname{var}\left(z_{t}\right)}{\operatorname{var}\left(a_{t}\right)+(1-\alpha)^{2} \operatorname{var}\left(z_{t}\right)}
\end{aligned}
$$

The size of the relative volatility measures above depends again on the relative importance of the shocks, as well as on the size of $\alpha$, the parameter determining the degree of diminishing returns to labor.

\footnotetext{
${ }^{26}$ If the original shocks are $\tilde{a}_{t}$ and $\tilde{z}_{t}$, then we define $a_{t}=\Omega \tilde{a}_{t}$ and $z_{t}=\Omega \tilde{z}_{t}$, where $\Omega=$ $1 /[1-(1-\alpha)(1-\eta)]$.

${ }^{27}$ This result is an implication of the logarithmic or 'balanced growth' preferences over consumption in combination with the absence of capital or any other intertemporal smoothing technology, and is similar to the 'neutrality result' in Shimer (2009).
} 


\subsection{Infinite Labor Market Frictions}

We can contrast the predictions of the frictionless model above, with the opposite extreme case of infinitely large labor market frictions, i.e. $g(H)=\infty$ if $H>0$. In this case, no new workers will be hired, so that by the aggregate resource constraint (31) $C_{t}=Y_{t}$, as in the frictionless case. For simplicity, also assume that the separation rate equals zero, $\delta=0$, so that employment is fixed. In this case, combining the production function (32) with the equilibrium condition for effort (25), and taking logarithms, ignoring constant terms and normalizing the variance of the shocks, ${ }^{28}$ we get:

$$
\begin{gathered}
e_{t}=(1-\eta) a_{t}+z_{t} \\
y_{t}=y_{t}-n_{t}=(1+\phi) a_{t}+(1-\alpha) \psi z_{t}
\end{gathered}
$$

Since employment is fixed, effort is now procyclical in response to both types of shocks, as all of the adjustment of labor input occurs on the intensive margin. With infinitely large labor market frictions, labor productivity is perfectly (positively) correlated with output. The correlation between productivity and employment, as well as the relative volatility of employment with respect to output equal zero. Finally, since the bargaining set is now infinitely wide, wages may be arbitrarily rigid, depending on the model parameters, so that the relative volatility of wages is also arbitrarily close to zero.

\subsection{Preview of the Results}

Comparing these predictions with those of the frictionless model in the previous subsection, it is clear that by moving from a completely rigid to a completely flexible labor market:

1. Labor productivity becomes less procyclical with respect to output.

2. Labor productivity goes from acyclical to countercyclical with respect to employment, depending on parameter values (a sufficient condition is logarithmic utility over consumption).

3. The relative volatility of employment increases.

4. The relative volatility of wages increases.

All four of these predictions are consistent with the data, as we documented in section 2. We are not arguing, of course, that the US labor market went from completely rigid to completely flexible. Rather, the argument so far is meant to illustrate that if the reduction in labor market frictions was large enough, it can qualitatively explain

\footnotetext{
${ }^{28}$ In this case, the normalization factor is $1 /[1+\phi-(1-\alpha)(1-\eta) \psi]$.
} 
the patterns we observe in the data. To answer the question whether we can also quantitatively match those patterns for reasonable parameter values, we now turn to a numerical analysis of the full model.

\subsection{Calibration}

We simulate data at quarterly frequency and calibrate accordingly. The calibration is summarized in Table 6. Many of the model's parameters can be easily calibrated to values that are standard in the literature. In this vein, we set the discount factor $\beta$ equal to 0.99 , assume logarithmic utility over consumption $(\eta=1)$, and assume $\alpha=1 / 3$ for the curvature of the production function to match the capital share in GDP.

In the model there is no difference between unemployment and non-participation. Therefore, we set the marginal utility from leisure $\gamma$ to match the employment-population ratio. Since the amount of labor market frictions affects this ratio as well, we calibrate to an employment-population ratio of 0.7 in the frictionless model. For the (gross) separation rate $\delta$, we assume $30.6 \%$ per quarter, calculated from the monthly worker flows in Shimer (2007). ${ }^{29}$

The calibration of the labor market frictions is crucial for the simulation exercise. We assume a quadratic cost function, $g(H)=\frac{1}{2} \kappa H^{2}$, see Yashiv (2010), and consider a range of values for $\kappa$ such that hiring costs vary from 0 to $3 \%$ of output. This range is based on Silva and Toledo (2009), who estimate the costs of hiring a new worker to be between 3 and $4.5 \%$ of the wage of a newly hired worker, see also Hagedorn and Manovskii (2008, p.1699). In steady state, the number of newly hired workers equals $\bar{H}=\delta \bar{N}$ per quarter, see (30). Wages, in the frictionless model without effort, approximately equal the marginal product of labor, $\bar{W}=(1-\alpha) \bar{Y} / \bar{N}$, see (36). Thus, hiring costs of $4.5 \%$ of the wage translate to total hiring costs of about $1 \%$ of output.

For the model's driving forces, we assume high persistence in both shocks, setting $\rho_{a}=0.97$ to match the first-order autocorrelation in Solow residuals, and $\rho_{z}=0.97$ to make sure that none of the results are driven by differences in persistence. Given those values, we calibrate $\sigma_{a}^{2}$ and $\sigma_{z}^{2}$ so that the frictionless version of the calibrated model matches the relative volatility of employment and predicts a standard deviation of $\log$ output of $1 \%$. The first target is justified by the observation that in this very simple model, preference shocks are a stand-in for all sources of misspecification that result in the unemployment volatility puzzle. The second target is arbitrarily chosen to emphasize that we consider this model mostly illustrative and not able to generate

\footnotetext{
${ }^{29}$ Shimer (2007) finds a monthly separation rate of $s_{m}=0.034$ and a monthly job finding rate of $f_{m}=0.45$. Then, the quarterly separation rate, the probability that a worker who is employed at the beginning of the quarter is no longer employed at the end of the quarter, is given by $s=s_{m}\left(1-f_{m}\right)^{2}+$ $\left(1-s_{m}\right) s_{m}\left(1-f_{m}\right)+\left(1-s_{m}\right)^{2} s_{m}+s_{m}^{2} f_{m}=0.0606$ and the quarterly job finding rate equals $f=$ $f_{m}\left(1-s_{m}\right)^{2}+\left(1-f_{m}\right) f_{m}\left(1-s_{m}\right)+\left(1-f_{m}\right)^{2} f_{m}+f_{m}^{2} s_{m}=0.802$. Since workers that are separated in a given quarter may find another job within that quarter, the gross separation rate is given by $\delta=s /(1-f)=0.306$.
} 
realistic predictions for the overall level of volatility in the economy.

For the parameters related to effort, we have very little guidance from previous literature. We normalize $\phi$ and $\zeta$ such that effort is expressed in utility units and equals 1 in the frictionless steady state. We treat the curvature of the production function in effort $\psi$ as a free parameter. Since we are mostly interested to illustrate the qualitative changes in the business cycle moments that the model can generate, we pick this parameter such that the model approximately replicates the second moments in the data. The testable prediction here is not whether the model can quantitatively match some or most of the second moments, but whether it can qualitatively generate all observed changes, changing only the labor market frictions.

\subsection{Simulation Results}

We now simulate the calibrated model in order to calculate the second moments of interest. We start with the model with flexible wages and show that a reduction in labor market frictions matches the data on the cyclicality of labor productivity and the relative volatility of labor input. Then we consider endogenous wage rigidity and show that the model can also match an increase in the relative volatility of wages, and -if endogenous wage rigidities are strong enough- can also generate a reduction in output volatility.

The model with flexible wages is close to log-linear and a first-order approximation captures well the dynamics generated by the model. However, the model with endogenous wage rigidity is non-linear, because the wage depends on the past wage $W_{t-1}$ and the bounds of the bargaining set $W_{t}^{U B}$ and $W_{t}^{L B}$, multiplied by the degree of rigidity $R_{t}$,

which itself depends again on $W_{t}$ and $W_{t}^{U B}$ and $W_{t}^{L B}$, see (26) and (27). If we were to log-linearize this wage rule, it would reduce to a partial adjustment rule with a constant degree of wage rigidity. Therefore, we use a second-order approximation of the policy functions. As an accuracy check, Figure 3 shows that a second-order approximation captures well the non-linear wage rule for $\rho=1$, but for $\rho=2$ or larger, a higher-order approximation is needed. We simulate the second-order approximation of the model 201, 000 periods, discarding the first 1,000 observations to eliminate the effect of the initial conditions. The results of this exercise are reported in Table 7.

\subsubsection{Flexible Wages}

Labor productivity is strongly procyclical in terms of its correlation with output in the model with a frictional labor market, and its procyclicality falls substantially as we reduce labor market frictions. The correlation of productivity with employment also falls, from around zero in the frictional labor market to countercyclical in the frictionless model. Both observations are consistent with the evidence. The reason for the decline in 
the procyclicality of productivity, is the increase in the relative volatility of employment, a result that is consistent with the data as well.

Two elements in the model are crucial for these results. First, the effort choice provides an intensive margin of adjustment for labor input. As frictions fall, it becomes optimal to adjust labor more through employment and less through effort. Thus, the volatility of employment increases more than that of output. Second, fluctuations in the model are driven by two types of shocks: technology shocks and preference shocks or labor supply shocks. In a one-shock model, the correlations between all variables would be close to either 1 or $-1 .^{30}$ In addition, if fluctuations were driven only by technology shocks then productivity could never be countercyclical, since employment would only fluctuate because of changes in labor demand, and the direct effect of technology on productivity would always prevail over the indirect effect of employment. It is important to stress, however, that our results are not driven by changes in the relative importance of both shocks, which we keep constant, but by the reduction in frictions, which changes the response of the economy conditional on each shock.

The model also predicts a small decrease in the relative volatility of wages and a small increase in the volatility of output. As argued in section 2.3, the first prediction is arguably not consistent with the data. The second one clearly is in contradiction with the well-documented reduction in output volatility, the so called Great Moderation. The decrease in the relative volatility of wages is driven by the fact that the wage is approximately proportional to the marginal product of labor. ${ }^{31}$ Since the marginal product of labor is proportional to output, but inversely proportional to employment, an increase in the relative volatility of employment must necessarily also decrease the relative volatility of wages. The increase in the volatility of output simply stems from the fact that reducing adjustment costs amplifies fluctuations in employment and therefore in output as well. In the next subsection we show that endogneous wage rigidities can easily reverse the predictions of the model for wages and possibly also bring the prediction for output volatility closer to the evidence.

\subsubsection{Endogenous Wage Rigidity}

The third panel in Table 7 presents the simulated second moments for the model with endogenous wage rigidity ( $\rho=1$ and $\bar{R}=0.95$ ). Comparing these moments to those for the flexible wage model, we see that the previously described predictions of the model for the cyclicality of labor productivity and the relative volatility of employment remain

\footnotetext{
${ }^{30}$ This is exactly true in a static, linear model. Our model is close to (log)linear and the version without capital and with flexible wages has only one state variable (employment), which has very fast transition dynamics.

${ }^{31} \mathrm{On}$ a frictional labor market, the wage is not equal to marginal product of labor, but as long as $\gamma$ is not too large, they are still proportional since workers and firms share the match surplus in equal proportions.
} 
virtually unchanged. The reason is that the fact that wages adjust when they get close to the bounds of the bargaining set mitigates the allocative effect of wage rigidity.

The prediction of the model for the relative volatility of wages, however, is reversed. The reduction in labor market frictions now increases the volatility of wages, although not by as much as in the data. To understand the mechanism behind this result, it is useful to consider the extreme case of endogenous wage rigidity $(\rho \rightarrow \infty)$, in which wages are completely fixed within the bargaining set, but adjust when they hit the bounds of the bargaining set. If frictions are high enough, so that the bargaining set is very wide, wages never adjust and their volatility is zero. On the other extreme, on a frictionless labor market, the bargaining set reduces to a point and wages behave as if they were flexible. Of course this effect is counteracted by the fact that the bounds of the bargaining set themselves are less volatile when frictions are lower. However, for our calibration of the parameters, the first effect dominates, as illustrated in Figure 4.

The small increase in output volatility in response to the reduction in labor market frictions is reversed to a small decrease for the model with endogenous wage rigidity. The reason is that increased wage flexibility dampens fluctuations in output in response to technology shocks. ${ }^{32}$ This result is consistent with a possible role of a decline in labor market frictions as a source of the Great Moderation. However, the effect is again much smaller than in the data. Thus, whereas we find this last result intuitively compelling, it is speculative in the sense that it is not clear whether it may be important quantitatively.

\section{Conclusions}

In this paper, we documented three changes in labor market dynamics over the postwar period in the US: the strong procyclicality of labor productivity has vanished, the volatility of employment has increased with respect to output, and the volatility of wages has increased relative to output and possibly even in absolute terms. We presented a model to argue that a more flexible labor market, modelled as a reduction in hiring costs, can explain all three facts. In addition, we showed that -in principle- the reduction in labor market frictions may also have contributed to the reduction in output volatility, which happened around the same time.

The intuition for why a reduction in labor market frictions increases the relative volatility of employment and reduces the procyclicality of labor productivity is straightforward and compelling. If there is another input into production that can be used at least partly as a substitute for labor, and which is not subject to the frictions, then a reduction in frictions will make that input less volatile, so that employment becomes more volatile with respect to output. In this paper, we refer to this other factor input as effort. But a very similar argument can be made for capacity utilization of capital.

\footnotetext{
${ }^{32}$ In reponse to preference shocks, which affect labor supply rather than labor demand, the reverse is true. However, the effect of technology shocks dominates that of preference shocks in our calibration.
} 
Given that capital does not fluctuate much at business cycle frequencies, the fact that the comovement of labor and output -and therefore labor productivity- has changed almost unavoidably leads to the conclusion that there must be another input into the production process.

Our argument that the reduction in labor market frictions is also responsible for the increase in the relative volatility of wages is more contentious. Our simulations of the model with endogenous wage ridigity show that this effect is qualitatively present, and can be made to dominate the direct effect on wages for reasonable parameter values. However, the increase in wage volatility in our simulations is much smaller than in the data. ${ }^{33}$ Potentially, we can amplify this effect by using a more non-linear wage rule, but then we also need to use a higher-order approximation of the model. While there is a compelling argument that wage rigidity is, at least to some degree, endogenous, it remains an open question quantitatively how important this mechanism is.

What have we learned about the possible causes of the Great Moderation? We showed that a reduction in labor market frictions, through an endogenous decrease in wage rigidity, can lead to a decrease in output volatility. However, this effect is small in our simulations, partly because the decrease in wage rigidity is relatively small (at least much smaller than in the data), but also because there is a direct effect of the reduction in labor market frictions that counteracts the effect of decreased wage rigidity: reduced frictions make labor more volatile, reducting the volatility of its marginal product. A further caveat against the conclusion that the Great Moderation is driven by a reduction in labor market frictions is that this story only works if technology shocks are relatively important as a source of business cycle fluctuation. The reason is that preference shocks act as labor supply shocks, so that wage rigidity dampens rather than amplifies fluctuations in employment in response to those shocks. Finally, reduced wage rigidity can only lead to reduced output volatility if the wage is allocative, i.e. if the reduction in wage rigidity applies to the wage of newly hired workers. We documented an increase in the relative volatility of wages of new hires, see section 2.3.2, but that increase is substantially smaller than for the average wage in the economy, casting further doubt on the importance of this mechanism for the Great Moderation.

If it is true that the US labor market become more flexible in the mid 80s, then what institutional change was responsible for it? It is tempting to attribute the lower labor market frictions to improvements in recruitment technologies, particularly web-based job search. However, that development, while potentially important, happened much later. ${ }^{34}$ Major changes on the US labor market in the mid 80s include the introduction of wrongful discharge laws in many states (Autor, Kerr, and Kugler (2007)), the increase

\footnotetext{
${ }^{33}$ At least than the data from the Labor Productivity and Cost program and the Current Population Survey. The data from the Current Employment Statistics show a decrease in the relative volatility of wages, see section 2.3, which our model has no trouble generating.

${ }^{34}$ The largest and one of the first internet recruitment providers, monster.com, started in 1994.
} 
in temporary help services and the decline of unionization. The introduction of the wrongful discharge legislation constitutes an increase in employment protection, which would increase rather than decrease frictions in our simple model. The increased share of temporary help workers (workers employed by a temporary help agency rather than directly by the employer where they work) is often seen as a response to increased employment protection and happened very gradually, see Estevão and Lach (1999), whereas the changes we document seem to have happened relatively suddenly around 1984 .

In terms of timing, the decline in union power lines up very well with our story. Farber and Western (2002) document a sharp decline in the number of certification elections in the early $80 \mathrm{~s}$ and interpret this as evidence for an "unfavourable political climate which raises the costs of unionization", induced by the Reagan's policies and in particular his handling of the air-traffic controllers' strike in 1981. Moreover, recent evidence suggests that union power is an important institution to explain differences in labor market volatility across countries and time periods, see Kent, Smith, and Holloway (2005), Bertola and LoPrete (2009) and Gnocchi and Pappa (2009). A logical next step for future research would be to write down a model with unions and endogenize the reduction in labor market frictions. 


\section{A Marginal Product and Disutility of Effort}

This appendix derives the marginal product of employment to the firm, equation (12), and the marginal disutility from employment, expressed in consumption terms, to the household, equation (16), if effort adjusts endogenously. From equations (4) and (2), it is straightforward differentation to decompose the total effect of employment on output and total effective labor supply into a direct effect and an effect through the endogenous response of effort.

$$
\begin{gathered}
\frac{d Y_{j t}}{d N_{j t}}=\frac{\partial Y_{j t}}{\partial N_{j t}}+\frac{\partial Y_{j t}}{\partial \mathcal{E}_{j t}} \frac{\partial \mathcal{E}_{j t}}{\partial N_{j t}}=\frac{(1-\alpha) Y_{j t}}{N_{j t}}\left(1+\psi \frac{N_{j t}}{\mathcal{E}_{j t}} \frac{\partial \mathcal{E}_{j t}}{\partial N_{j t}}\right) \\
\frac{d L_{h t}}{d N_{h t}}=\frac{\partial L_{h t}}{\partial N_{h t}}+\frac{\partial L_{h t}}{\partial \mathcal{E}_{h t}} \frac{\partial \mathcal{E}_{h t}}{\partial N_{h t}}=\frac{1}{1+\zeta}\left[1+\zeta \mathcal{E}_{h t}^{1+\phi}\left(1+(1+\phi) \frac{N_{h t}}{\mathcal{E}_{h t}} \frac{\partial \mathcal{E}_{h t}}{\partial N_{h t}}\right)\right]
\end{gathered}
$$

Here, $\mathcal{E}_{j t}$ denotes the effort of all workers $i$ that are employed in firm $j$ and $\mathcal{E}_{h t}$ the effort of all workers that are members of household $h$.

To find the response of effort to changes in employment that firm and household face, we use the condition that the marginal disutility from effort of a given worker $i$ (expressed in consumption terms) from equation (8), in equilibrium must equal the marginal productivity of that worker to the firm from equation (9).

$$
\mathcal{E}_{i t}^{1+\phi-\psi}=\frac{\psi(1+\zeta)}{(1+\phi) \zeta} \frac{Z_{t}}{\gamma C_{h t}^{\eta}}(1-\alpha) A_{t}\left(\int_{0}^{N_{j t}} \mathcal{E}_{v t}^{\psi} d v\right)^{-\alpha}
$$

First, suppose firm $j$ considers employing $N_{j t}$ workers, given that all other firms employ the equilibrium number of workers $N_{t}$. Because there are infinitely many firms, firm $j$ 's decision to employ $N_{j t} \neq N_{t}$ workers does not affect the fraction of household $h$ 's members that are employed, so that by the assumption of perfect risk-sharing within the household, the consumption of workers in firm $j$ is not affected, $C_{h t}=C_{t}$. Substituting this, as well as the condition that all workers in firm $j$ exert the same amount of effort, $\mathcal{E}_{i t}=\mathcal{E}_{j t}$ for all $i \in\left[0, N_{j t}\right]$, the effort condition becomes,

$$
\mathcal{E}_{j t}^{1+\phi-\psi}=\frac{\psi(1+\zeta)}{(1+\phi) \zeta} \frac{Z_{t}}{\gamma C_{t}^{\eta}}(1-\alpha) A_{t}\left(\mathcal{E}_{j t}^{\psi} N_{j t}\right)^{-\alpha}
$$

so that the elasticity of effort in a given firm $j$ with respect to employment in that firm, is given by

$$
\frac{N_{j t}}{\mathcal{E}_{j t}} \frac{\partial \mathcal{E}_{j t}}{\partial N_{j t}}=-\frac{\alpha}{1+\phi-(1-\alpha) \psi}
$$

Substituting this elasticity into equation (48) above, gives expression (12) in the text.

Next, suppose household $h$ considers having $N_{h t}$ employed workers, given that all other households have $N_{t}$ employed workers. Because there are infinitely many households, household's $h$ 's decision to have a fraction of $N_{h t} \neq N_{t}$ of its members employed, 
does not affect the level of employment in any firm $N_{j t}=N_{t}$. Furthermore, although the effort level of worker $i$ may change because of household $h$ 's decision, effort of all other workers in firm $j$, who are members of different households, is unaffected, $\mathcal{E}_{i t}=\mathcal{E}_{h t}$ and $\mathcal{E}_{i^{\prime} t}=\mathcal{E}_{t}$ for $i^{\prime} \neq i$. Thus, the effort condition becomes,

$$
\mathcal{E}_{h t}^{1+\phi-\psi}=\frac{\psi(1+\zeta)}{(1+\phi) \zeta} \frac{Z_{t}}{\gamma C_{h t}^{\eta}}(1-\alpha) A_{t}\left(\mathcal{E}_{t}^{\psi} N_{t}\right)^{-\alpha}
$$

and the elasticity of effort exerted by members of household $h$ with respect to employment in that household, using equation (3), is given by,

$$
\frac{N_{h t}}{\mathcal{E}_{h t}} \frac{\partial \mathcal{E}_{h t}}{\partial N_{h t}}=\frac{C_{h t}}{\mathcal{E}_{h t}} \frac{\partial \mathcal{E}_{h t}}{\partial C_{h t}} \cdot \frac{N_{h t}}{C_{h t}} \frac{\partial C_{h t}}{\partial N_{h t}}=-\frac{\eta}{1+\phi-\psi} \frac{W_{h t} N_{h t}}{C_{h t}}=-\frac{\eta}{1+\phi-\psi}
$$

Substituting this elasticity into equation (49) above, gives expression (16) in the text. 


\section{References}

Arias, A., G. Hansen, and L. E. Ohanian (2007). Why have business cycle fluctuations become less volatile? Economic Theory 32(1), 43-58.

Autor, D. H., W. R. Kerr, and A. D. Kugler (2007). Does employment protection reduce productivity? evidence from US states. Economic Journal 117(June).

Barnichon, R. (2008). Productivity, aggregate demand and unemployment fluctuations. Board of governors of the federal reserve system: Finance and economics discussion series 2008-47.

Barro, R. J. (1977). Long-term contracting, sticky prices, and monetary policy. Journal of Monetary Economics 3(3).

Basu, S. (1996). Procyclical productivity: increasing returns or cyclical utilization? Quarterly Journal of Economics $111(3)$.

Basu, S. and J. Fernald (1997). Returns to scale in U.S. production: Estimates and implications. Journal of Political Economy 105, 249-283.

Basu, S. and M. S. Kimball (1997). Cyclical productivity with unobserved input variation. NBER working paper 5915.

Bernanke, B. and M. Parkinson (1991). Procyclical labor productivity and competing theories of the business cycle: Some evidence from interwar u.s. manufacturing industries. Journal of Political Economy 99(3), 439-459.

Bertola, G. and A. LoPrete (2009). Reforms, finance, and current accounts. Upublished manuscript.

Bils, M. and J.-O. Cho (1994). Cyclical factor utilization. Journal of Monetary Economics 33(2), 319-354.

Blanchard, O. and J. Galí (2007). Real wage rigidities and the new keynesian model. Journal of Money, Credit and Banking 39(s1), 35-65.

Blanchard, O. and J. Galí (2008). The macroeconomic effects of oil price shocks: Why are the 2000s so different from the 1970s? CREI working paper.

Blanchard, O. and M. Watson (1986). Are business cycles all alike? In R. Gordon (Ed.), Continuity and Change in the American Business Cycle. NBER and the University of Chicago Press.

Burnside, C., M. Eichenbaum, and S. Rebelo (1993). Labor hoarding and the business cycle. Journal of Political Economy 101(2), 245-273.

Champagne, J. and A. Kurmann (2010). The great increase in relative wage volatility in the United States. Unpublished manuscript. 
Christiano, L. and M. Eichenbaum (1992). Current Real Business Cycle theories and aggregate labor market fluctuations. American Economic Review 82(3).

Christoffel, K. and K. Kuester (2008). Resuscitating the wage channel in models with unemployment fluctuations. Journal of Monetary Economics 55(5), 865-887.

Clarida, R., J. Galí, and M. Gertler (2000). The science of monetary policy: A new Keynesian perspective. Journal of Economic Literature XXXVII(December 1999).

Estevão, M. and S. Lach (1999). The evolution of the demand for temporary help supply employment in the United States. NBER working paper 7427.

Fair, R. (1969). The Short-run Demand for Workers and Hours. Amsterdam: NorthHolland.

Farber, H. S. and B. Western (2002). Ronald Reagan and the politics of declining union organization. British Journal of Industrial Relations 40(3).

Fay, J. A. and J. L. Medoff (1985). Labor and output over the business cycle: Some direct evidence. American Economic Review 75(4), 638-655.

Francis, N. and V. Ramey (2008). Measures of hours per capita and their implications for the technology-hours debate. Unpublished manuscript.

Galí;, J. and L. Gambetti (2009). On the sources of the great moderation. American Economic Journal: Macroeconomics 1(1), 26-57.

Gertler, M. and A. Trigari (2009). Unemployment fluctuations with staggered nash wage bargaining. Journal of Political Economy 117(1), 38-86.

Gnocchi, S. and E. Pappa (2009). Do labor market rigidities matter for business cycles? yes they do. Unpublished manuscript.

Gordon, R. J. (2004). Are procyclical productivity fluctuations a figment of measurement error. In R. Gordon (Ed.), Productivity Growth, Inflation, and Unemployment, pp. 239-272. Cambridge University Press.

Gordon, R. J. (2010). Okun's law, productivity innovations, and conundrums in business cycle dating. American Economic Review: Papers and Proceedings 100(2).

Gourio, F. (2007). Labor market flexibility and the Great Moderation. Unpublished manuscript.

Haefke, C., M. Sonntag, and T. van Rens (2008). Wage rigidity and job creation. CREI working paper.

Hagedorn, M. and I. Manovskii (2008). The cyclical behavior of equilibrium unemployment and vacancies revisited. American Economic Review 98(4), 1692-1706.

Hall, R. E. (1988). The relation between price and marginal cost in U.S. industry. Journal of Political Economy 96(5), 921-947. 
Hall, R. E. (2003). Wage determination and employment fluctuations. Working Paper 9967, NBER.

Hall, R. E. (2005). Employment fluctuations with equilibrium wage stickiness. American Economic Review 95(1), 50-65.

Hall, R. E. (2007). How much do we understand about the modern recession? Brookings Papers on Economic Activity 2, 13-28.

Hall, R. E. and P. R. Milgrom (2008). The limited influence of unemployment on the wage bargain. American Economic Review 98(4), 1653-74.

Kent, C., K. Smith, and J. Holloway (2005). Declining output volatility: What role for structural change? In C. Kent and D. Norman (Eds.), The Changing Nature of the Business Cycle. Reserve Bank of Australia.

McConell, M. M. and G. Pérez-Quirós (2000). Output fluctuations in the United States: What has changed since the early 1980's? American Economic Review $90(5), 1464-1476$.

Mehran, H. and J. Tracy (2001). The effect of employee stock options on the evolution of compensation in the 1990s. Economic Policy Review, Federal Reserve Bank of New York Dec, 17-34.

Nucci, F. and M. Riggi (2009). The Great Moderation and changes in the structure of labor compensation. Unpublished manuscript.

Oi, W. Y. (1962). Labor as a quasi-fixed factor. Journal of Political Economy 70, $538-555$.

Pissarides, C. A. (2009). The unemployment volatility puzzle: Is wage stickiness the answer? Walras-Bowley lecture, North American summer meetings of the Econometric Society, Duke University. Econometrica 77(5), 1339-1369.

Rogerson, R. and R. Shimer (2010). Search in macroeconomic models of the labor market. In O. Ashenfelter and D. Card (Eds.), Handbook of Labor Economics, volume 4 , pp. forthcoming.

Rotemberg, J. and L. Summers (1990). Inflexible prices and procyclical productivity. Quarterly Journal of Economics 105 (November), 851-874.

Shapiro, M. (1993). Cyclical productivity and the workweek of capital. American Economic Review: Papers and Proceedings 83, 229-233.

Shea, J. (1999). What do technology shocks do? NBER macroeconomics annual 13, $275-310$

Shimer, R. (2005). The cyclical behavior of equilibrium unemployment and vacancies. American Economic Review 95(1), 25-49. 
Shimer, R. (2007). Reassessing the ins and outs of unemployment. NBER Working Papers 13421, National Bureau of Economic Research, Inc.

Shimer, R. (2009). Labor Markets and Business Cycles. Princeton University Press, CREI Lectures in Macroeconomics.

Silva, J. I. and M. Toledo (2009). Labor turnover costs and the cyclical behavior of vacancies and unemployment. Macroeconomic Dynamics 13(S1), 76-96.

Solow, R. M. (1964). On the short-run relation between employment and output. Presidential address to the econometric society.

Stiroh, K. J. (2009). Volatility accounting: A production perspective on increased economic stability. Journal of the European Economic Association 7(4), 671-696.

Stock, J. and M. Watson (2002). Has the Business Cycle Changed and Why? MIT Press.

Stock, J. H. and M. W. Watson (1999). Business cycle fluctuations in U.S. macroeconomic time series. In J. B. Taylor and M. Woodford (Eds.), Handbook of Macroeconomics, volume 1A, pp. 3-64. Elsevier.

Thomas, J. and T. Worrall (1988). Self-enforcing wage contracts. Review of Economic Studies 55(4), 541-54.

Uhlig, H. and Y. Xu (1996). Effort and the cycle. Tilburg University, Center for Economic Research discussion paper 1996-49.

Uren, L. (2008). Inequality, volatility and labour market efficiency. B.E. Journals, Topics in Macroeconomics 8(1).

Wen, Y. (2004). What does it take to explain procyclical productivity. B.E. Journals, Contributions to Macroeconomics 4(1).

Yashiv, E. (2010). On the joint behavior of hiring and investment. Unpublished manuscript. 
Table 1. The Vanishing Procyclicality of Labor Productivity

\begin{tabular}{|c|c|c|c|c|c|c|}
\hline & \multicolumn{3}{|c|}{ Corr with output } & \multicolumn{3}{|c|}{ Corr with labor input } \\
\hline & Pre- 84 & Post- 84 & Change & Pre- 84 & Post-84 & Change \\
\hline \multicolumn{7}{|c|}{ Output per hour } \\
\hline \multirow[t]{2}{*}{$\mathrm{BP}$} & 0.60 & 0.25 & -0.35 & 0.19 & -0.40 & -0.59 \\
\hline & {$[0.06]$} & {$[0.07]$} & {$[0.09]$} & {$[0.09]$} & {$[0.07]$} & {$[0.11]$} \\
\hline \multirow[t]{2}{*}{$4 \mathrm{D}$} & 0.62 & 0.18 & -0.44 & 0.09 & -0.54 & -0.62 \\
\hline & {$[0.05]$} & {$[0.09]$} & {$[0.10]$} & {$[0.07]$} & {$[0.08]$} & {$[0.11]$} \\
\hline \multicolumn{7}{|c|}{ Output per worker } \\
\hline \multirow[t]{2}{*}{$\mathrm{BP}$} & 0.78 & 0.60 & -0.18 & 0.31 & -0.15 & -0.47 \\
\hline & {$[0.04]$} & {$[0.05]$} & {$[0.06]$} & {$[0.08]$} & {$[0.10]$} & [0.13] \\
\hline \multirow[t]{2}{*}{$4 \mathrm{D}$} & 0.76 & 0.46 & -0.30 & 0.13 & -0.33 & -0.46 \\
\hline & {$[0.03]$} & {$[0.09]$} & {$[0.09]$} & {$[0.08]$} & {$[0.11]$} & {$[0.14]$} \\
\hline
\end{tabular}

Standard errors in brackets are calculated from the variance-covariance matrix of the second moments using the delta method. Data for the private sector are from the BLS labor productivity and cost program (LPC) and refer to the private sector. Labor input is total hours worked in the first panel and employment in the second panel, consistent with the definition of labor productivity. The sample period is 1949-2007. 
Table 2. The Rising Volatility of Labor Input

\begin{tabular}{r|rrr|rrr}
\hline \hline & \multicolumn{3}{|c|}{ Std. Dev. } & \multicolumn{3}{c}{ Relative Std. Dev. } \\
& Pre-84 & Post-84 & Ratio & Pre-84 & Post-84 & Ratio \\
\hline \multicolumn{6}{c}{ Employment (private sector) } \\
\hline BP & 1.57 & 0.91 & 0.58 & 0.66 & 0.81 & 1.23 \\
& {$[0.08]$} & {$[0.05]$} & {$[0.04]$} & {$[0.03]$} & {$[0.05]$} & {$[0.09]$} \\
$4 \mathrm{D}$ & 2.44 & 1.54 & 0.63 & 0.66 & 0.94 & 1.43 \\
& {$[0.13]$} & {$[0.12]$} & {$[0.06]$} & {$[0.03]$} & {$[0.08]$} & {$[0.15]$} \\
\hline Hours (private sector) & & & & \\
\hline BP & 1.93 & 1.18 & 0.61 & 0.81 & 1.06 & 1.30 \\
& {$[0.09]$} & {$[0.06]$} & {$[0.04]$} & {$[0.03]$} & {$[0.05]$} & {$[0.08]$} \\
$4 \mathrm{D}$ & 2.94 & 1.92 & 0.65 & 0.79 & 1.17 & 1.48 \\
& {$[0.15]$} & {$[0.13]$} & {$[0.06]$} & {$[0.04]$} & {$[0.09]$} & {$[0.13]$} \\
\hline Hours (total economy) & \multicolumn{3}{c}{} \\
\hline BP & 1.68 & 0.85 & 0.51 & 0.71 & 0.76 & 1.07 \\
& {$[0.08]$} & {$[0.04]$} & {$[0.04]$} & {$[0.03]$} & {$[0.04]$} & {$[0.07]$} \\
$4 \mathrm{D}$ & 2.56 & 1.47 & 0.57 & 0.69 & 0.89 & 1.30 \\
& {$[0.14]$} & {$[0.10]$} & {$[0.05]$} & {$[0.03]$} & {$[0.07]$} & {$[0.11]$} \\
\hline \hline
\end{tabular}

Standard errors in brackets are calculated from the variance-covariance matrix of the second moments using the delta method. Data for the private sector are from the BLS labor productivity and cost program (LPC) and refer to the private sector. Hours (total economy) is an unpublished series for economy-wide hours constructed by the BLS and used in Francis and Ramey (2008). The sample period is 1949-2007. 
Table 3. The Rising Volatility of Wages

\begin{tabular}{c|rrr|rrr}
\hline \hline & \multicolumn{3}{|c|}{ Std. Dev. } & \multicolumn{3}{c}{ Relative Std. Dev. } \\
& Pre-84 & Post-84 & Ratio & Pre-84 & Post-84 & Ratio \\
\hline Compensation per hour (NIPA, private sector) \\
\hline BP & 0.71 & 0.99 & 1.38 & 0.30 & 0.88 & 2.93 \\
& {$[0.05]$} & {$[0.06]$} & {$[0.12]$} & {$[0.02]$} & {$[0.07]$} & {$[0.31]$} \\
$4 \mathrm{D}$ & 1.72 & 1.61 & 0.93 & 0.46 & 0.98 & 2.11 \\
& {$[0.12]$} & {$[0.11]$} & {$[0.09]$} & {$[0.04]$} & {$[0.12]$} & {$[0.32]$} \\
\hline Compensation per hour (NIPA, total economy) \\
\hline BP & 0.78 & 0.86 & 1.10 & 0.33 & 0.76 & 2.32 \\
& {$[0.05]$} & {$[0.05]$} & {$[0.10]$} & {$[0.02]$} & {$[0.07]$} & {$[0.24]$} \\
$4 \mathrm{D}$ & 1.85 & 1.57 & 0.85 & 0.50 & 0.95 & 1.92 \\
& {$[0.10]$} & {$[0.10]$} & {$[0.07]$} & {$[0.03]$} & {$[0.12]$} & {$[0.26]$} \\
\hline Earnings per hour $($ CES, private sector) & & \\
\hline BP & 1.38 & 0.40 & 0.29 & 0.54 & 0.34 & 0.63 \\
& {$[0.12]$} & {$[0.02]$} & {$[0.03]$} & {$[0.04]$} & {$[0.03]$} & {$[0.07]$} \\
$4 \mathrm{D}$ & 1.85 & 0.97 & 0.52 & 0.52 & 0.56 & 1.08 \\
& {$[0.14]$} & {$[0.08]$} & {$[0.06]$} & {$[0.05]$} & {$[0.06]$} & {$[0.16]$} \\
\hline Compensation per hour (NIPA, private sector, CPI deflator) \\
\hline BP & 0.83 & 0.99 & 1.20 & 0.35 & 0.89 & 2.54 \\
& {$[0.05]$} & {$[0.06]$} & {$[0.10]$} & {$[0.02]$} & {$[0.08]$} & {$[0.27]$} \\
4D & 1.93 & 1.70 & 0.88 & 0.52 & 1.04 & 1.99 \\
& {$[0.13]$} & {$[0.12]$} & {$[0.08]$} & {$[0.04]$} & {$[0.13]$} & {$[0.30]$} \\
\hline \hline
\end{tabular}

Standard errors in brackets are calculated from the variance-covariance matrix of the second moments using the delta method. Wages are calculated as real compensation per hour. Compensation and hours data for the private sector are from the BLS labor productivity and cost program. Compensation data for NIPA compensation are combined with an unpublished economy-wide series for hours constructed by the BLS and used in Francis and Ramey (2008). Compensation from the establishment survey or Current Employment Statistics (CES) exclude non-wage payments. The sample period is 1949-2007 for the NIPA and 1965-2004 for the CES-based series. 
Table 4. The Rising Volatility of Wages: Newly Hired Workers

\begin{tabular}{r|rrr|rrr}
\hline \hline & \multicolumn{3}{|c|}{ Std. Dev. } & \multicolumn{3}{c}{ Relative Std. Dev. } \\
& Pre-84 & Post-84 & Ratio & Pre-84 & Post-84 & Ratio \\
\hline \multicolumn{6}{c}{ Compensation per hour (NIPA, private sector) } \\
\hline BP & 0.46 & 1.01 & 2.20 & 0.18 & 0.88 & 4.78 \\
& {$[0.06]$} & {$[0.06]$} & {$[0.29]$} & {$[0.04]$} & {$[0.08]$} & {$[1.01]$} \\
$4 \mathrm{D}$ & 1.71 & 1.63 & 0.95 & 0.37 & 0.97 & 2.62 \\
& {$[0.13]$} & {$[0.11]$} & {$[0.10]$} & {$[0.05]$} & {$[0.13]$} & {$[0.50]$} \\
\hline Mean usual hourly earnings (CPS) & & \\
\hline BP & 0.49 & 0.54 & 1.10 & 0.20 & 0.47 & 2.39 \\
& {$[0.05]$} & {$[0.03]$} & {$[0.13]$} & {$[0.04]$} & {$[0.04]$} & {$[0.48]$} \\
4D & 1.48 & 1.27 & 0.86 & 0.32 & 0.76 & 2.36 \\
& {$[0.14]$} & {$[0.11]$} & {$[0.11]$} & {$[0.05]$} & {$[0.09]$} & {$[0.46]$} \\
\hline Mean usual hourly earnings newly hired workers (CPS) \\
\hline BP & 1.42 & 0.67 & 0.47 & 0.57 & 0.58 & 1.03 \\
& {$[0.16]$} & {$[0.05]$} & {$[0.07]$} & {$[0.08]$} & {$[0.05]$} & {$[0.17]$} \\
4D & 4.49 & 2.77 & 0.62 & 0.97 & 1.65 & 1.69 \\
& {$[0.60]$} & {$[0.26]$} & {$[0.10]$} & {$[0.17]$} & {$[0.24]$} & {$[0.38]$} \\
\hline \hline
\end{tabular}

Standard errors in brackets are calculated from the variance-covariance matrix of the second moments using the delta method. CPS wage data are earnings per hour from the outgoing rotation groups, which limits the period for which quarterly data are available to after 1979. Wage series are constructed as in Haefke, Sonntag, and van Rens (2008) but are not corrected for composition bias for comparability with other data sources. However, keeping the composition of the labor force contant in terms of education, experience and demographic characteristics makes very little differerence for the results presented here. The sample period is 1980-2005. 
Table 5. Additional Business Cycle Statistics

A. Volatility output and productivity

\begin{tabular}{|c|c|c|c|c|c|c|}
\hline & \multicolumn{3}{|c|}{ Std. Dev. } & \multicolumn{3}{|c|}{ Relative Std. Dev. } \\
\hline & Pre-84 & Post-84 & Ratio & Pre-84 & Post-84 & Ratio \\
\hline \multicolumn{7}{|c|}{ Output } \\
\hline \multirow[t]{2}{*}{ BP } & 2.37 & 1.12 & 0.47 & & & \\
\hline & {$[0.13]$} & {$[0.06]$} & {$[0.04]$} & & & \\
\hline \multirow[t]{2}{*}{$4 \mathrm{D}$} & 3.72 & 1.64 & 0.44 & & & \\
\hline & {$[0.18]$} & {$[0.16]$} & {$[0.05]$} & & & \\
\hline \multicolumn{7}{|c|}{ Output per worker } \\
\hline \multirow[t]{2}{*}{$\mathrm{BP}$} & 1.36 & 0.81 & 0.60 & 0.57 & 0.72 & 1.26 \\
\hline & [0.08] & {$[0.05]$} & {$[0.05]$} & {$[0.03]$} & {$[0.06]$} & {$[0.12]$} \\
\hline \multirow[t]{2}{*}{$4 \mathrm{D}$} & 2.50 & 1.26 & 0.51 & 0.67 & 0.77 & 1.15 \\
\hline & {$[0.14]$} & {$[0.08]$} & {$[0.04]$} & {$[0.03]$} & {$[0.07]$} & {$[0.13]$} \\
\hline
\end{tabular}

B. Correlations

\begin{tabular}{|c|c|c|c|c|c|c|}
\hline & \multicolumn{3}{|c|}{ Corr with output } & \multicolumn{3}{|c|}{ Corr with employment } \\
\hline & Pre- 84 & Post-84 & Change & Pre-84 & Post-84 & Change \\
\hline \multicolumn{7}{|c|}{ Employment (private sector) } \\
\hline \multirow[t]{2}{*}{$\mathrm{BP}$} & 0.84 & 0.70 & -0.14 & & & \\
\hline & {$[0.02]$} & [0.05] & {$[0.06]$} & & & \\
\hline \multirow[t]{2}{*}{$4 \mathrm{D}$} & 0.75 & 0.69 & -0.06 & & & \\
\hline & {$[0.03]$} & {$[0.05]$} & {$[0.06]$} & & & \\
\hline \multicolumn{7}{|c|}{ Compensation per hour (NIPA, private sector) } \\
\hline \multirow[t]{2}{*}{$\mathrm{BP}$} & 0.40 & 0.28 & -0.12 & 0.20 & -0.11 & -0.31 \\
\hline & {$[0.08]$} & {$[0.09]$} & {$[0.12]$} & {$[0.09]$} & {$[0.09]$} & {$[0.13$} \\
\hline \multirow[t]{2}{*}{$4 \mathrm{D}$} & 0.30 & 0.11 & -0.20 & -0.02 & -0.29 & -0.27 \\
\hline & {$[0.07]$} & {$[0.07]$} & {$[0.10]$} & {$[0.07]$} & {$[0.08]$} & {$[0.11$} \\
\hline
\end{tabular}

Standard errors in brackets are calculated from the variance-covariance matrix of the second moments using the delta method. See tables 1, 2 and 3 for data sources. The sample period is $1949-2007$. 
Table 6. Model Calibration

\begin{tabular}{|c|c|c|}
\hline & Parameter & Target \\
\hline \multirow[t]{3}{*}{ Utility: } & $\beta=0.99$ & quarterly data \\
\hline & $\eta=1$ & log utility over consumption \\
\hline & $\gamma=1.24$ & frictionless employment population ratio $\bar{N}=0.7$ \\
\hline Production: & $f(N)=N^{1-\alpha}, \alpha=1 / 3$ & capital share \\
\hline \multirow[t]{3}{*}{ Effort: } & $\zeta=0.299$ & normalization: frictionless $\overline{\mathcal{E}}=1$ \\
\hline & $\phi=0$ & normalization so that $\mathcal{E}$ is in utils \\
\hline & $\psi=0.3$ & total curvature $\phi+\psi$ is a free parameter \\
\hline \multirow[t]{3}{*}{ Frictions: } & $\delta=0.306$ & gross quarterly separations, Shimer (2007) \\
\hline & $g(H)=\frac{1}{2} \kappa H^{2}$ & quadratic adjustment costs, Yashiv (2010) \\
\hline & $\kappa=0-1.35$ & frictions $0-3 \%$ of output, Silva and Toledo (2009) \\
\hline \multirow[t]{2}{*}{ Shocks: } & $\rho_{A}=0.97, \sigma_{A}=0.186$ & normalization: $\operatorname{sd}(y)=1 \%$ \\
\hline & $\rho_{z}=0.97, \sigma_{z}=0.173$ & $\operatorname{sd}(n) / \operatorname{sd}(y)=0.66$ \\
\hline
\end{tabular}


Table 7. Simulation results

\begin{tabular}{|c|c|c|c|c|c|c|}
\hline & $\begin{array}{l}\mathrm{empl} / \mathrm{pop} \\
\operatorname{ratio} \bar{N}\end{array}$ & $\begin{array}{l}\text { correlation pr } \\
\text { with output }\end{array}$ & $\begin{array}{l}\text { coductivity } \\
\text { with empl }\end{array}$ & $\begin{array}{l}\text { relative } \\
\text { empl } n_{t}\end{array}$ & $\begin{array}{l}\text { std.dev. } \\
\text { wage } w_{t}\end{array}$ & $\begin{array}{l}\text { std.dev. } \\
\text { output } y_{t}\end{array}$ \\
\hline \multicolumn{7}{|l|}{ Data } \\
\hline Pre-84 & & 0.78 & 0.31 & 0.66 & 0.30 & \\
\hline Post-84 & & 0.60 & -0.15 & 0.81 & 0.88 & \\
\hline \multicolumn{7}{|c|}{ "Model with flexible wages } \\
\hline frictions $3 \%$ & 0.59 & 0.76 & -0.05 & 0.66 & 0.89 & 1.00 \\
\hline frictions $2 \%$ & 0.63 & 0.70 & -0.15 & 0.72 & 0.88 & 0.99 \\
\hline frictions $1 \%$ & 0.66 & 0.65 & -0.25 & 0.78 & 0.89 & 1.00 \\
\hline frictionless & 0.70 & 0.60 & -0.31 & 0.84 & 0.86 & 1.02 \\
\hline \multicolumn{7}{|c|}{ Model with endogenous wage rigidity $(\rho=1, \bar{R}=0.95)$} \\
\hline frictions $3 \%$ & 0.59 & 0.74 & 0.13 & 0.66 & 0.71 & 1.00 \\
\hline frictions $2 \%$ & 0.63 & 0.71 & 0.06 & 0.71 & 0.70 & 1.00 \\
\hline frictions $1 \%$ & 0.66 & 0.64 & -0.05 & 0.77 & 0.71 & 1.00 \\
\hline frictionless & 0.70 & 0.66 & -0.28 & 0.79 & 0.88 & 0.91 \\
\hline
\end{tabular}

Moments for the model are based on simulated time series of 200,000 quarters. We simulate the model for 201,000 quarters but ignore the first 1,000 quarters to eliminate the effect of the initial conditions. Numbers in bold are calibration targets. 
Figure 1. The Vanishing Procyclicality of Labor Productivity

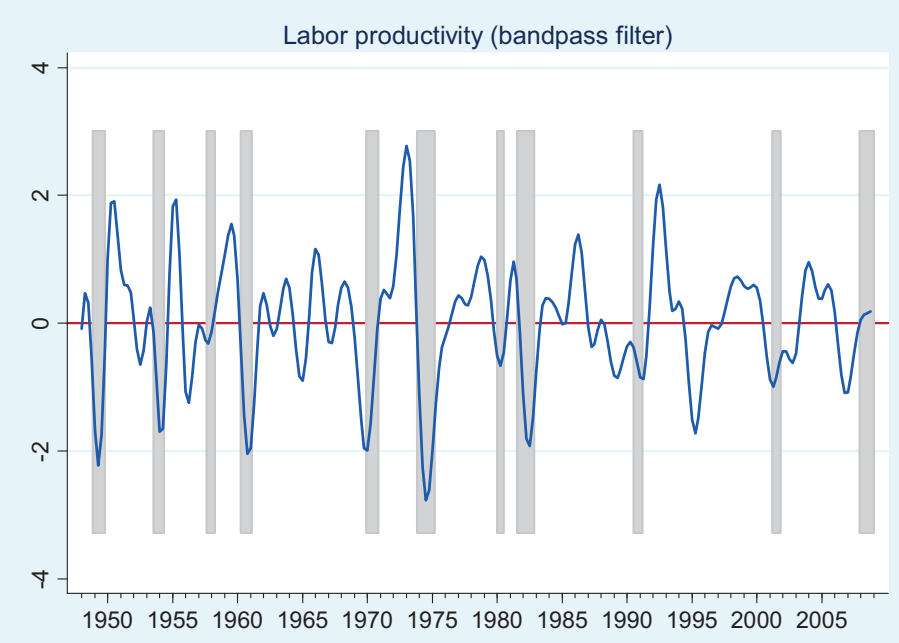

Output per hour in the US private sector. Shaded areas are NBER recessions.

Figure 2. The Vanishing Procyclicality of Labor Productivity: Rolling Correlations

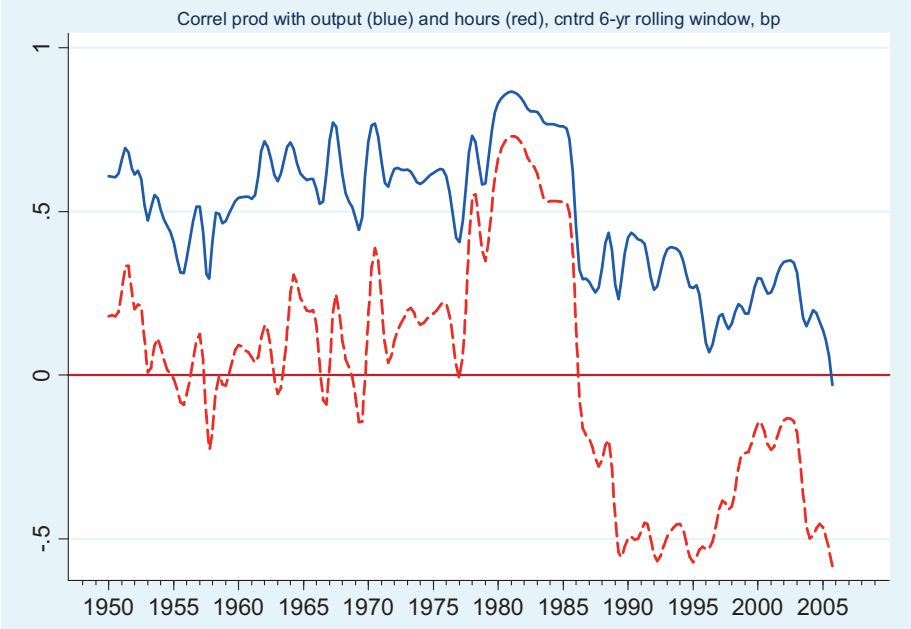

Correlations are calculated in a centered 6-year rolling window of quarterly bandpassfiltered data. 
Figure 3. Endogenous Wage Rigidity: Wage Rule

$$
\rho=1 \text { (quadratic) }
$$

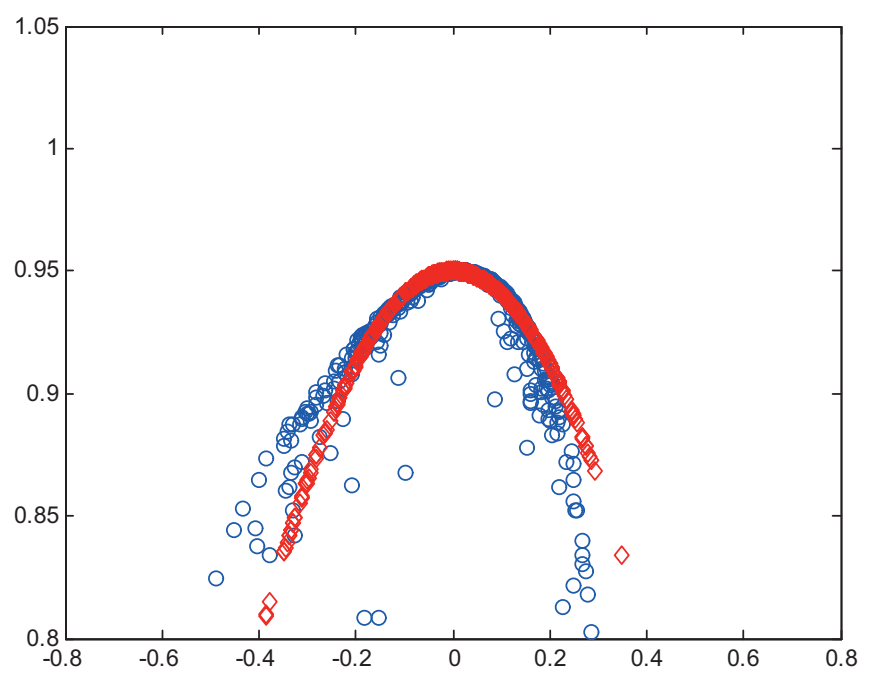

$$
\rho=2 \text { (quartic) }
$$

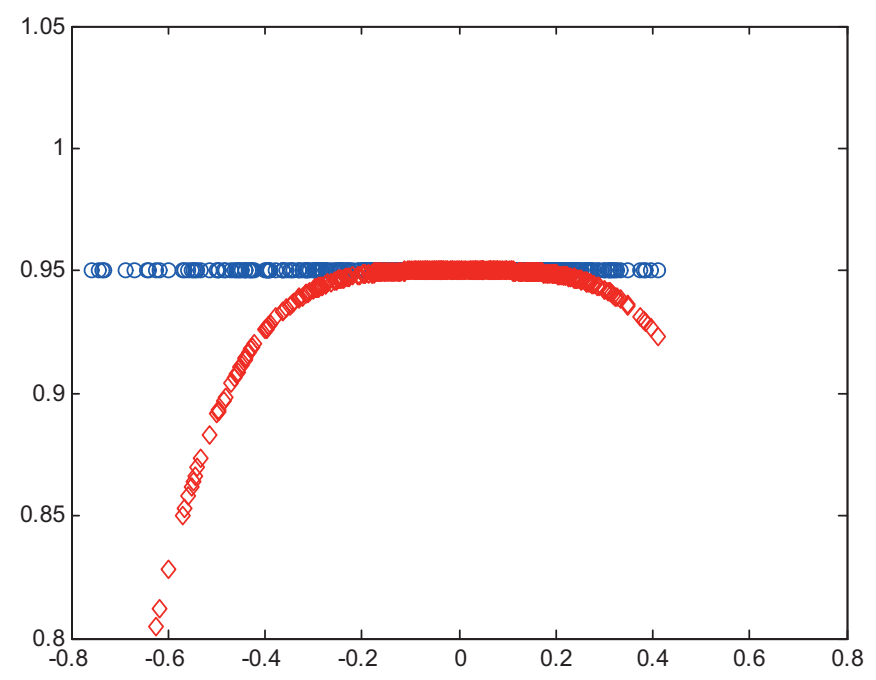

Wage rigidity $R_{t}$ as a function of the relative distance of the wage from the center of the bargaining set $\left(W_{t}-W_{t}^{*}\right) / \frac{1}{2}\left(W_{t}^{U B}-W_{t}^{L B}\right)$, see equation (23). The red diamonds represent the theoretical non-linear relation. The blue circles are simulated data from a second-order approximation of the model. In these graphs, frictions are set to $0.3 \%$ of output. 
Figure 4. Endogenous Wage Rigity: Simulated Wage Data Large frictions ( $1 \%$ of output)

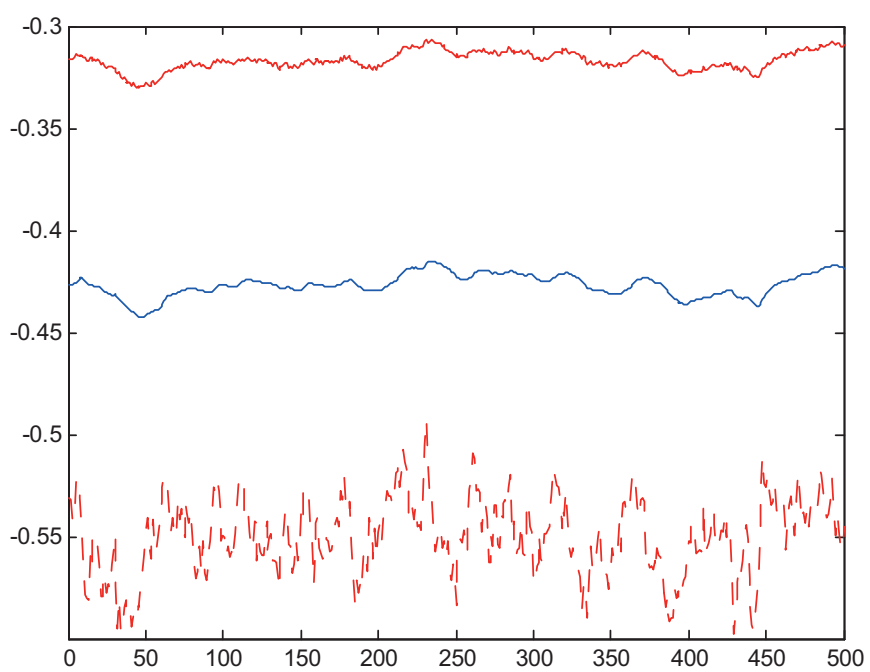

Small frictions $(0.2 \%$ of output)

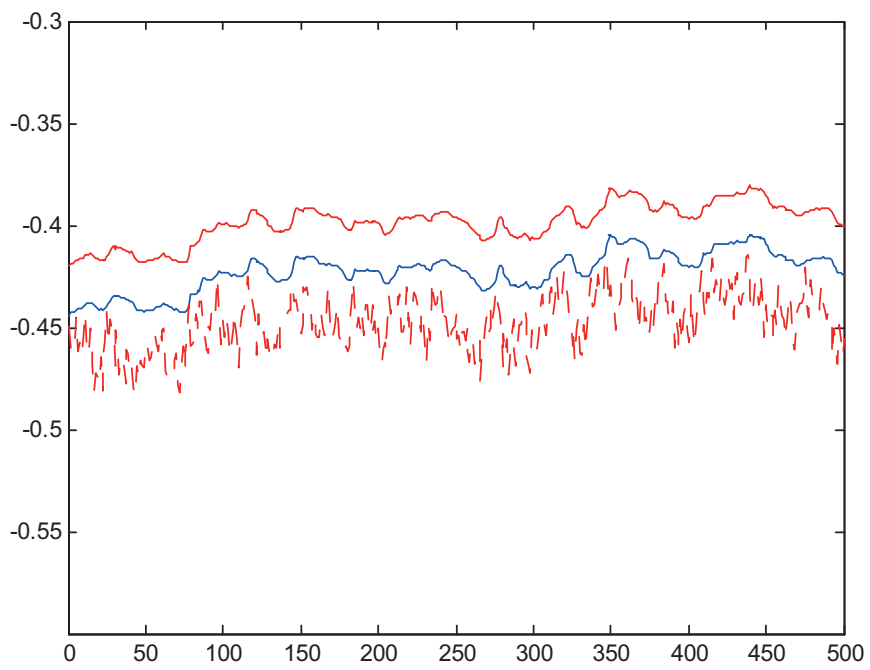

Simulated wage paths for the model with large frictions and small frictions. In this calibration, the wage is more volatile if frictions are smaller. 


\section{B Additional tables and figures (not for publication)}

Extended Table 1. The Vanishing Procyclicality of Labor Productivity

Output per hour

\begin{tabular}{|r|r|r|r|r|r|r|r|r|r|r|}
\hline & & \multicolumn{3}{|c|}{ Correlation with Output } & \multicolumn{3}{|c|}{ Correlation with Empl. } & \multicolumn{2}{|c|}{ Correlation with Hours } \\
\hline & & Pre-84 & Post-84 & Change & Pre-84 & Post-84 & Change & Pre-84 & Post-84 & Change \\
\hline $1949-2007$ & BP & 0.60 & 0.25 & -0.35 & 0.09 & -0.47 & -0.56 & 0.19 & -0.40 & -0.59 \\
\hline & & {$[0.06]$} & {$[0.07]$} & {$[0.09]$} & {$[0.09]$} & {$[0.07]$} & {$[0.12]$} & {$[0.09]$} & {$[0.07]$} & {$[0.11]$} \\
\hline & $\mathrm{HP}$ & 0.61 & 0.04 & -0.57 & 0.07 & -0.60 & -0.67 & 0.17 & -0.56 & -0.73 \\
\hline & & {$[0.05]$} & {$[0.09]$} & {$[0.10]$} & {$[0.08]$} & {$[0.06]$} & {$[0.10]$} & {$[0.08]$} & {$[0.07]$} & {$[0.10]$} \\
\hline & $4 \mathrm{D}$ & 0.62 & 0.18 & -0.44 & -0.03 & -0.53 & -0.51 & 0.09 & -0.54 & -0.62 \\
\hline & & {$[0.05]$} & {$[0.09]$} & {$[0.10]$} & {$[0.08]$} & {$[0.08]$} & {$[0.11]$} & {$[0.07]$} & {$[0.08]$} & {$[0.11]$} \\
\hline $1965-2004$ & $\mathrm{BP}$ & 0.65 & 0.29 & -0.36 & 0.16 & -0.44 & -0.60 & 0.28 & -0.36 & -0.63 \\
\hline & & {$[0.07]$} & {$[0.07]$} & {$[0.10]$} & {$[0.13]$} & {$[0.08]$} & {$[0.15]$} & {$[0.12]$} & {$[0.08]$} & {$[0.15]$} \\
\hline & $\mathrm{HP}$ & 0.64 & 0.04 & -0.60 & 0.11 & -0.59 & -0.70 & 0.23 & -0.54 & -0.77 \\
\hline & & {$[0.06]$} & {$[0.09]$} & {$[0.11]$} & {$[0.10]$} & {$[0.07]$} & {$[0.12]$} & {$[0.10]$} & {$[0.07]$} & {$[0.12]$} \\
\hline & $4 \mathrm{D}$ & 0.62 & 0.12 & -0.50 & -0.01 & -0.56 & -0.55 & 0.11 & -0.54 & -0.65 \\
\hline & & {$[0.07]$} & {$[0.09]$} & {$[0.12]$} & {$[0.10]$} & {$[0.08]$} & {$[0.13]$} & {$[0.10]$} & {$[0.09]$} & {$[0.13]$} \\
\hline $1975-1994$ & $\mathrm{BP}$ & 0.78 & 0.34 & -0.45 & 0.52 & -0.39 & -0.92 & 0.61 & -0.36 & -0.98 \\
\hline & & {$[0.05]$} & {$[0.09]$} & {$[0.11]$} & {$[0.09]$} & {$[0.11]$} & {$[0.15]$} & {$[0.08]$} & {$[0.11]$} & {$[0.13]$} \\
\hline & $\mathrm{HP}$ & 0.66 & -0.01 & -0.68 & 0.26 & -0.65 & -0.91 & 0.39 & -0.60 & -0.99 \\
\hline & & {$[0.08]$} & {$[0.14]$} & {$[0.17]$} & {$[0.13]$} & {$[0.08]$} & {$[0.15]$} & {$[0.12]$} & {$[0.09]$} & {$[0.15]$} \\
\hline & $4 \mathrm{D}$ & 0.54 & 0.20 & -0.33 & -0.03 & -0.51 & -0.48 & 0.08 & -0.52 & -0.60 \\
\hline & & {$[0.11]$} & {$[0.11]$} & {$[0.16$} & {$[0.14]$} & {$[0.14]$} & {$[0.20]$} & {$[0.14]$} & {$[0.14]$} & {$[0.20]$} \\
\hline
\end{tabular}

Output per worker

\begin{tabular}{|r|r|r|r|r|r|r|r|r|r|r|r|}
\hline & & \multicolumn{3}{|c|}{ Correlation with Output } & \multicolumn{3}{|c|}{ Correlation with Empl. } & \multicolumn{3}{|c|}{ Correlation with Hours } \\
\hline & & Pre-84 & Post-84 & Change & Pre-84 & Post-84 & Change & Pre-84 & Post-84 & Change \\
\hline $1949-2007$ & $\mathrm{BP}$ & 0.78 & 0.60 & -0.18 & 0.31 & -0.15 & -0.47 & 0.44 & 0.01 & -0.43 \\
\hline & & {$[0.04]$} & {$[0.05]$} & {$[0.06]$} & {$[0.08]$} & {$[0.10]$} & {$[0.13]$} & {$[0.07]$} & {$[0.10]$} & {$[0.12]$} \\
\hline & $\mathrm{HP}$ & 0.77 & 0.40 & -0.37 & 0.25 & -0.32 & -0.57 & 0.40 & -0.18 & -0.58 \\
\hline & & {$[0.03]$} & {$[0.08]$} & {$[0.09]$} & {$[0.07]$} & {$[0.09]$} & {$[0.11]$} & {$[0.07]$} & {$[0.10]$} & {$[0.12]$} \\
\hline & $4 \mathrm{D}$ & 0.76 & 0.46 & -0.30 & 0.13 & -0.33 & -0.46 & 0.30 & -0.21 & -0.51 \\
\hline & & {$[0.03]$} & {$[0.09]$} & {$[0.09]$} & {$[0.08]$} & {$[0.11]$} & {$[0.14]$} & {$[0.07]$} & {$[0.12]$} & {$[0.14]$} \\
\hline $1965-2004$ & $\mathrm{BP}$ & 0.78 & 0.63 & -0.15 & 0.33 & -0.13 & -0.46 & 0.47 & 0.06 & -0.41 \\
\hline & & {$[0.05]$} & {$[0.05]$} & {$[0.07]$} & {$[0.11]$} & {$[0.10]$} & {$[0.15]$} & {$[0.10]$} & {$[0.10]$} & {$[0.14]$} \\
\hline & $\mathrm{HP}$ & 0.76 & 0.41 & -0.35 & 0.25 & -0.31 & -0.55 & 0.41 & -0.15 & -0.56 \\
\hline & & {$[0.04]$} & {$[0.08]$} & {$[0.09]$} & {$[0.09]$} & {$[0.09]$} & {$[0.13]$} & {$[0.08]$} & {$[0.11]$} & {$[0.14]$} \\
\hline & 4D & 0.75 & 0.43 & -0.31 & 0.12 & -0.33 & -0.45 & 0.30 & -0.20 & -0.50 \\
\hline & & {$[0.04]$} & {$[0.09]$} & {$[0.10]$} & {$[0.10]$} & {$[0.12]$} & {$[0.15]$} & {$[0.09]$} & {$[0.12]$} & {$[0.15]$} \\
\hline $1975-1994$ & $\mathrm{BP}$ & 0.86 & 0.70 & -0.16 & 0.62 & -0.03 & -0.65 & 0.73 & 0.10 & -0.63 \\
\hline & & {$[0.03]$} & {$[0.05]$} & {$[0.06]$} & {$[0.07]$} & {$[0.16]$} & {$[0.18]$} & {$[0.06]$} & {$[0.15]$} & {$[0.16]$} \\
\hline & $\mathrm{HP}$ & 0.74 & 0.36 & -0.38 & 0.35 & -0.38 & -0.73 & 0.50 & -0.22 & -0.72 \\
\hline & & {$[0.06]$} & {$[0.13]$} & {$[0.15]$} & {$[0.11]$} & {$[0.12]$} & {$[0.16]$} & {$[0.10]$} & {$[0.15]$} & {$[0.17]$} \\
\hline & 4D & 0.69 & 0.49 & -0.19 & 0.13 & -0.30 & -0.43 & 0.28 & -0.18 & -0.46 \\
\hline & & {$[0.08]$} & {$[0.12]$} & {$[0.14]$} & {$[0.13]$} & {$[0.19]$} & {$[0.23]$} & {$[0.12]$} & {$[0.19]$} & {$[0.23]$} \\
\hline
\end{tabular}

Standard errors in brackets are calculated from the variance-covariance matrix of the second moments using the delta method. Data for the private sector are from the BLS labor productivity and cost program (LPC) and refer to the private sector. 
Extended Table 2. The Rising Volatility of Labor Input

Employment (private sector)

\begin{tabular}{|c|c|c|c|c|c|c|c|}
\hline & & \multicolumn{3}{|c|}{ Std. Dev. } & \multicolumn{3}{|c|}{ Relative Std. Dev. } \\
\hline & & Pre-84 & Post-84 & Ratio & Pre-84 & Post-84 & Ratio \\
\hline \multirow[t]{6}{*}{$1949-2007$} & $\mathrm{BP}$ & 1.57 & 0.91 & 0.58 & 0.66 & 0.81 & 1.23 \\
\hline & & {$[0.08]$} & {$[0.05]$} & {$[0.04]$} & {$[0.03]$} & [0.05] & {$[0.09]$} \\
\hline & $\mathrm{HP}$ & 1.62 & 1.16 & 0.72 & 0.66 & 0.97 & 1.47 \\
\hline & & {$[0.08]$} & {$[0.07]$} & {$[0.06]$} & {$[0.03]$} & [0.06] & [0.12] \\
\hline & $4 \mathrm{D}$ & 2.44 & 1.54 & 0.63 & 0.66 & 0.94 & 1.43 \\
\hline & & [0.13] & [0.12] & {$[0.06]$} & {$[0.03]$} & {$[0.08]$} & {$[0.15]$} \\
\hline \multirow[t]{6}{*}{1975 - 1994} & $\mathrm{BP}$ & 1.71 & 0.83 & 0.49 & 0.65 & 0.71 & 1.11 \\
\hline & & [0.13] & {$[0.07]$} & {$[0.06]$} & {$[0.04]$} & {$[0.06]$} & {$[0.11]$} \\
\hline & $\mathrm{HP}$ & 2.10 & 1.27 & 0.60 & 0.71 & 1.01 & 1.41 \\
\hline & & [0.15] & {$[0.11]$} & {$[0.07]$} & {$[0.05]$} & [0.10] & {$[0.17]$} \\
\hline & $4 D$ & 2.94 & 1.60 & 0.54 & 0.73 & 0.91 & 1.24 \\
\hline & & {$[0.20]$} & [0.13] & {$[0.06]$} & {$[0.06]$} & {$[0.12]$} & {$[0.20]$} \\
\hline
\end{tabular}

Hours (private sector)

\begin{tabular}{|c|c|c|c|c|c|c|c|}
\hline & & \multicolumn{3}{|c|}{ Std. Dev. } & \multicolumn{3}{|c|}{ Relative Std. Dev. } \\
\hline & & Pre-84 & Post-84 & Ratio & Pre- 84 & Post- 84 & Ratio \\
\hline \multirow[t]{6}{*}{$1949-2007$} & $\mathrm{BP}$ & 1.93 & 1.18 & 0.61 & 0.81 & 1.06 & 1.30 \\
\hline & & [0.09] & {$[0.06]$} & {$[0.04]$} & [0.03] & {$[0.05]$} & {$[0.08]$} \\
\hline & $\mathrm{HP}$ & 1.96 & 1.44 & 0.73 & 0.80 & 1.20 & 1.50 \\
\hline & & [0.10] & {$[0.08]$} & {$[0.05]$} & {$[0.03]$} & [0.07] & {$[0.10]$} \\
\hline & $4 \mathrm{D}$ & 2.94 & 1.92 & 0.65 & 0.79 & 1.17 & 1.48 \\
\hline & & [0.15] & [0.13] & {$[0.06]$} & {$[0.04]$} & [0.09] & {$[0.13]$} \\
\hline \multirow[t]{6}{*}{$1975-1994$} & $\mathrm{BP}$ & 2.08 & 1.18 & 0.57 & 0.79 & 1.01 & 1.28 \\
\hline & & [0.15] & {$[0.09]$} & {$[0.06]$} & [0.03] & {$[0.07]$} & {$[0.10]$} \\
\hline & $\mathrm{HP}$ & 2.40 & 1.58 & 0.66 & 0.81 & 1.25 & 1.54 \\
\hline & & [0.19] & [0.13] & {$[0.08]$} & {$[0.04]$} & [0.11] & {$[0.15]$} \\
\hline & $4 \mathrm{D}$ & 3.39 & 2.01 & 0.59 & 0.85 & 1.15 & 1.36 \\
\hline & & {$[0.27]$} & [0.15] & {$[0.07]$} & {$[0.06]$} & [0.14] & {$[0.20]$} \\
\hline
\end{tabular}

Hours (total economy)

\begin{tabular}{|r|r|r|r|r|r|r|r|}
\hline & \multicolumn{3}{|c|}{ Std. Dev. } & \multicolumn{3}{|c|}{ Relative Std. Dev. } \\
\hline & & Pre-84 & Post-84 & Ratio & Pre-84 & Post-84 & Ratio \\
\hline $1949-2007$ & BP & 1.68 & 0.85 & 0.51 & 0.71 & 0.76 & 1.07 \\
\hline & & {$[0.08]$} & {$[0.04]$} & {$[0.04]$} & {$[0.03]$} & {$[0.04]$} & {$[0.07]$} \\
\hline & HP & 1.71 & 1.06 & 0.62 & 0.70 & 0.89 & 1.27 \\
\hline & & {$[0.09]$} & {$[0.07]$} & {$[0.05]$} & {$[0.03]$} & {$[0.05]$} & {$[0.09]$} \\
\hline & $4 D$ & 2.56 & 1.47 & 0.57 & 0.69 & 0.89 & 1.30 \\
\hline & & {$[0.14]$} & {$[0.10]$} & {$[0.05]$} & {$[0.03]$} & {$[0.07]$} & {$[0.11]$} \\
\hline $1975-1994$ & BP & 1.63 & 0.94 & 0.58 & 0.62 & 0.81 & 1.31 \\
\hline & & {$[0.11]$} & {$[0.06]$} & {$[0.06]$} & {$[0.03]$} & {$[0.06]$} & {$[0.11]$} \\
\hline & HP & 1.98 & 1.22 & 0.61 & 0.67 & 0.97 & 1.44 \\
\hline & & {$[0.15]$} & {$[0.10]$} & {$[0.07]$} & {$[0.03]$} & {$[0.09]$} & {$[0.15]$} \\
\hline & 4D & 2.67 & 1.54 & 0.58 & 0.67 & 0.88 & 1.32 \\
\hline & & {$[0.20]$} & {$[0.11]$} & {$[0.06]$} & {$[0.05]$} & {$[0.11]$} & {$[0.19]$} \\
\hline
\end{tabular}

Standard errors in brackets are calculated from the variance-covariance matrix of the second moments using the delta method. Data for the private sector are from the BLS labor productivity and cost program (LPC) and refer to the private sector. Hours (total economy) is an unpublished series for economy-wide hours constructed by the BLS and used in Francis and Ramey (2008). 
Extended Table 3. The Rising Volatility of Wages

Compensation per hour (NIPA, private sector)

\begin{tabular}{|c|c|c|c|c|c|c|c|}
\hline & & \multicolumn{3}{|c|}{ Std. Dev. } & \multicolumn{3}{|c|}{ Relative Std. Dev. } \\
\hline & & Pre-84 & Post-84 & Ratio & Pre-84 & Post- 84 & Ratio \\
\hline \multirow[t]{6}{*}{ 1949- 2007} & BP & 0.71 & 0.99 & 1.38 & 0.30 & 0.88 & 2.93 \\
\hline & & {$[0.05]$} & [0.06] & {$[0.12]$} & [0.02] & {$[0.07]$} & {$[0.31]$} \\
\hline & $\mathrm{HP}$ & 0.85 & 1.03 & 1.21 & 0.35 & 0.86 & 2.48 \\
\hline & & {$[0.06]$} & {$[0.06]$} & [0.11] & [0.03] & {$[0.08]$} & [0.29] \\
\hline & $4 \mathrm{D}$ & 1.72 & 1.61 & 0.93 & 0.46 & 0.98 & 2.11 \\
\hline & & [0.12] & [0.11] & {$[0.09]$} & {$[0.04]$} & [0.12] & {$[0.32]$} \\
\hline \multirow[t]{6}{*}{$1965-2004$} & $\mathrm{BP}$ & 0.73 & 1.03 & 1.42 & 0.29 & 0.89 & 3.09 \\
\hline & & {$[0.07]$} & [0.06] & [0.16] & [0.02] & [0.08] & [0.35] \\
\hline & $\mathrm{HP}$ & 0.80 & 1.07 & 1.35 & 0.31 & 0.86 & 2.80 \\
\hline & & {$[0.06]$} & {$[0.07]$} & [0.14] & {$[0.03]$} & {$[0.08]$} & {$[0.37]$} \\
\hline & $4 \mathrm{D}$ & 1.43 & 1.64 & 1.15 & 0.40 & 0.96 & 2.39 \\
\hline & & {$[0.10]$} & [0.12] & [0.11] & [0.03] & [0.13] & [0.38] \\
\hline \multirow[t]{6}{*}{$1975-1994$} & $\mathrm{BP}$ & 0.65 & 1.22 & 1.86 & 0.25 & 1.04 & 4.22 \\
\hline & & {$[0.07]$} & [0.08] & {$[0.24]$} & {$[0.02]$} & [0.13] & {$[0.67]$} \\
\hline & $\mathrm{HP}$ & 0.76 & 1.12 & 1.46 & 0.26 & 0.89 & 3.43 \\
\hline & & {$[0.08]$} & {$[0.09]$} & [0.18] & {$[0.03]$} & [0.10] & {$[0.60]$} \\
\hline & $4 \mathrm{D}$ & 1.42 & 1.75 & 1.24 & 0.35 & 1.00 & 2.82 \\
\hline & & [0.11] & {$[0.17]$} & {$[0.15]$} & {$[0.04]$} & {$[0.21]$} & {$[0.68]$} \\
\hline
\end{tabular}

Compensation per hour (NIPA, total economy)

\begin{tabular}{|c|c|c|c|c|c|c|c|}
\hline & & \multicolumn{3}{|c|}{ Std. Dev. } & \multicolumn{3}{|c|}{ Relative Std. Dev. } \\
\hline & & Pre-84 & Post- 84 & Ratio & Pre-84 & Post-84 & Ratio \\
\hline \multirow[t]{6}{*}{$1949-2007$} & $\mathrm{BP}$ & 0.78 & 0.86 & 1.10 & 0.33 & 0.76 & 2.32 \\
\hline & & {$[0.05]$} & {$[0.05]$} & {$[0.10]$} & {$[0.02]$} & {$[0.07]$} & {$[0.24]$} \\
\hline & HP & 0.84 & 0.95 & 1.14 & 0.34 & 0.80 & 2.33 \\
\hline & & {$[0.05]$} & {$[0.08]$} & {$[0.11]$} & {$[0.02]$} & {$[0.09]$} & {$[0.30]$} \\
\hline & $4 \mathrm{D}$ & 1.85 & 1.57 & 0.85 & 0.50 & 0.95 & 1.92 \\
\hline & & {$[0.10]$} & [0.10] & {$[0.07]$} & [0.03] & [0.12] & {$[0.26]$} \\
\hline \multirow[t]{6}{*}{$1965-2004$} & $\mathrm{BP}$ & 0.84 & 0.91 & 1.09 & 0.33 & 0.78 & 2.36 \\
\hline & & {$[0.08]$} & [0.05] & {$[0.12]$} & [0.02] & {$[0.07]$} & {$[0.27]$} \\
\hline & $\mathrm{HP}$ & 0.86 & 0.99 & 1.14 & 0.33 & 0.79 & 2.37 \\
\hline & & {$[0.08]$} & {$[0.08]$} & {$[0.14]$} & {$[0.03]$} & [0.09] & {$[0.35]$} \\
\hline & $4 \mathrm{D}$ & 1.67 & 1.59 & 0.95 & 0.47 & 0.92 & 1.98 \\
\hline & & [0.11] & [0.11] & {$[0.09]$} & [0.04] & [0.12] & {$[0.30]$} \\
\hline \multirow[t]{6}{*}{$1975-1994$} & $\mathrm{BP}$ & 0.78 & 1.08 & 1.39 & 0.29 & 0.93 & 3.15 \\
\hline & & {$[0.10]$} & {$[0.07]$} & {$[0.20]$} & [0.03] & [0.11] & {$[0.52]$} \\
\hline & $\mathrm{HP}$ & 0.81 & 1.09 & 1.34 & 0.28 & 0.86 & 3.14 \\
\hline & & {$[0.08]$} & [0.13] & {$[0.20]$} & [0.03] & [0.14] & {$[0.62]$} \\
\hline & $4 \mathrm{D}$ & 1.68 & 1.86 & 1.11 & 0.42 & 1.06 & 2.53 \\
\hline & & {$[0.14]$} & {$[0.17]$} & {$[0.14]$} & {$[0.05]$} & {$[0.21]$} & {$[0.58]$} \\
\hline
\end{tabular}

continued on next page ... 
Earnings per hour (CES, private sector)

\begin{tabular}{|r|r|r|r|r|r|r|r|}
\hline & & \multicolumn{3}{|c|}{ Std. Dev. } & \multicolumn{3}{|c|}{ Relative Std. Dev. } \\
\hline & & Pre-84 & Post-84 & Ratio & Pre-84 & Post-84 & Ratio \\
\hline $1965-2004$ & BP & 1.38 & 0.40 & 0.29 & 0.54 & 0.34 & 0.63 \\
\hline & & {$[0.12]$} & {$[0.02]$} & {$[0.03]$} & {$[0.04]$} & {$[0.03]$} & {$[0.07]$} \\
\hline & $\mathrm{HP}$ & 1.27 & 0.46 & 0.36 & 0.49 & 0.37 & 0.75 \\
\hline & & {$[0.11]$} & {$[0.03]$} & {$[0.04]$} & {$[0.05]$} & {$[0.04]$} & {$[0.10]$} \\
\hline & $4 \mathrm{D}$ & 1.85 & 0.97 & 0.52 & 0.52 & 0.56 & 1.08 \\
\hline & & {$[0.14]$} & {$[0.08]$} & {$[0.06]$} & {$[0.05]$} & {$[0.06]$} & {$[0.16]$} \\
\hline $1975-1994$ & $\mathrm{BP}$ & 1.32 & 0.36 & 0.27 & 0.50 & 0.30 & 0.61 \\
\hline & & {$[0.15]$} & {$[0.04]$} & {$[0.04]$} & {$[0.05]$} & {$[0.04]$} & {$[0.11]$} \\
\hline & $\mathrm{HP}$ & 1.21 & 0.35 & 0.29 & 0.41 & 0.27 & 0.67 \\
\hline & & {$[0.14]$} & {$[0.05]$} & {$[0.05]$} & {$[0.05]$} & {$[0.04]$} & {$[0.13]$} \\
\hline & 4D & 1.63 & 0.82 & 0.50 & 0.41 & 0.47 & 1.14 \\
\hline & {$[0.19]$} & {$[0.10]$} & {$[0.08]$} & {$[0.05]$} & {$[0.07]$} & {$[0.23]$} \\
\hline
\end{tabular}

Compensation per hour (NIPA, private sector, output deflator)

\begin{tabular}{|r|r|r|r|r|r|r|r|}
\hline & \multicolumn{3}{|c|}{ Std. Dev. } & \multicolumn{3}{|c|}{ Relative Std. Dev. } \\
\hline & & Pre-84 & Post-84 & Ratio & Pre-84 & Post-84 & Ratio \\
\hline $1949-2007$ & $\mathrm{BP}$ & 0.67 & 0.95 & 1.42 & 0.28 & 0.85 & 3.02 \\
\hline & & {$[0.04]$} & {$[0.07]$} & {$[0.13]$} & {$[0.02]$} & {$[0.08]$} & {$[0.34]$} \\
\hline & $\mathrm{HP}$ & 0.82 & 1.06 & 1.30 & 0.33 & 0.89 & 2.65 \\
\hline & & {$[0.06]$} & {$[0.07]$} & {$[0.12]$} & {$[0.03]$} & {$[0.08]$} & {$[0.32]$} \\
\hline & $4 \mathrm{D}$ & 1.48 & 1.65 & 1.11 & 0.40 & 1.00 & 2.51 \\
\hline & & {$[0.11]$} & {$[0.11]$} & {$[0.11]$} & {$[0.04]$} & {$[0.13]$} & {$[0.39]$} \\
\hline $1975-1994$ & $\mathrm{BP}$ & 0.62 & 1.22 & 1.97 & 0.23 & 1.04 & 4.47 \\
\hline & & {$[0.08]$} & {$[0.10]$} & {$[0.29]$} & {$[0.03]$} & {$[0.14]$} & {$[0.80]$} \\
\hline & $\mathrm{HP}$ & 0.70 & 1.10 & 1.57 & 0.24 & 0.88 & 3.68 \\
\hline & & {$[0.09]$} & {$[0.10]$} & {$[0.23]$} & {$[0.04]$} & {$[0.11]$} & {$[0.70]$} \\
\hline & $4 \mathrm{D}$ & 1.26 & 1.69 & 1.34 & 0.32 & 0.96 & 3.05 \\
\hline & & {$[0.09]$} & {$[0.18]$} & {$[0.17]$} & {$[0.04]$} & {$[0.21]$} & {$[0.74]$} \\
\hline
\end{tabular}

Compensation per hour (NIPA, private sector, CPI deflator)

\begin{tabular}{|r|r|r|r|r|r|r|r|}
\hline & \multicolumn{3}{|c|}{ Std. Dev. } & \multicolumn{3}{|c|}{ Relative Std. Dev. } \\
\hline & & Pre-84 & Post-84 & Ratio & Pre-84 & Post-84 & Ratio \\
\hline $1949-2007$ & BP & 0.83 & 0.99 & 1.20 & 0.35 & 0.89 & 2.54 \\
\hline & & {$[0.05]$} & {$[0.06]$} & {$[0.10]$} & {$[0.02]$} & {$[0.08]$} & {$[0.27]$} \\
\hline & $\mathrm{HP}$ & 0.96 & 1.04 & 1.08 & 0.39 & 0.87 & 2.21 \\
\hline & & {$[0.06]$} & {$[0.06]$} & {$[0.09]$} & {$[0.03]$} & {$[0.08]$} & {$[0.26]$} \\
\hline & $4 \mathrm{D}$ & 1.93 & 1.70 & 0.88 & 0.52 & 1.04 & 1.99 \\
\hline & & {$[0.13]$} & {$[0.12]$} & {$[0.08]$} & {$[0.04]$} & {$[0.13]$} & {$[0.30]$} \\
\hline $1975-1994$ & $\mathrm{BP}$ & 1.00 & 1.19 & 1.19 & 0.38 & 1.02 & 2.68 \\
\hline & & {$[0.09]$} & {$[0.09]$} & {$[0.13]$} & {$[0.04]$} & {$[0.13]$} & {$[0.44]$} \\
\hline & $\mathrm{HP}$ & 1.16 & 1.14 & 0.98 & 0.39 & 0.90 & 2.30 \\
\hline & & {$[0.09]$} & {$[0.09]$} & {$[0.11]$} & {$[0.05]$} & {$[0.11]$} & {$[0.40]$} \\
\hline & 4D & 2.01 & 1.94 & 0.96 & 0.50 & 1.10 & 2.20 \\
\hline & {$[0.24]$} & {$[0.19]$} & {$[0.15]$} & {$[0.07]$} & {$[0.23]$} & {$[0.56]$} \\
\hline
\end{tabular}

Standard errors in brackets are calculated from the variance-covariance matrix of the second moments using the delta method. Wages are calculated as real compensation per hour. Compensation and hours data for the private sector are from the BLS labor productivity and cost program. Compensation data for NIPA compensation are combined with an unpublished economy-wide series for hours constructed by the BLS and used in Francis and Ramey (2008). Compensation from the establishment survey or Current Employment Statistics (CES) exclude non-wage payments. 
Extended Table 4. The Rising Volatility of Wages: Newly Hired Workers

Compensation per hour (NIPA, private sector)

\begin{tabular}{|c|c|c|c|c|c|c|c|}
\hline & & \multicolumn{3}{|c|}{ Std. Dev. } & \multicolumn{3}{|c|}{ Relative Std. Dev. } \\
\hline & & Pre-84 & Post-84 & Ratio & Pre-84 & Post-84 & Ratio \\
\hline \multirow[t]{6}{*}{$1980-2005$} & $\mathrm{BP}$ & 0.46 & 1.01 & 2.20 & 0.18 & 0.88 & 4.78 \\
\hline & & {$[0.06]$} & [0.06] & {$[0.29]$} & [0.04] & {$[0.08]$} & [1.01] \\
\hline & $\mathrm{HP}$ & 0.59 & 1.05 & 1.78 & 0.20 & 0.86 & 4.22 \\
\hline & & {$[0.08]$} & {$[0.07]$} & {$[0.27]$} & {$[0.05]$} & {$[0.08]$} & [1.09] \\
\hline & $4 \mathrm{D}$ & 1.71 & 1.63 & 0.95 & 0.37 & 0.97 & 2.62 \\
\hline & & [0.13] & [0.11] & {$[0.10]$} & [0.05] & [0.13] & {$[0.50]$} \\
\hline
\end{tabular}

Usual hourly earnings (CPS)

\begin{tabular}{|c|c|c|c|c|c|c|c|}
\hline & & \multicolumn{3}{|c|}{ Std. Dev. } & \multicolumn{3}{|c|}{ Relative Std. Dev. } \\
\hline & & Pre-84 & Post-84 & Ratio & Pre-84 & Post-84 & Ratio \\
\hline \multirow[t]{6}{*}{ Median } & $\mathrm{BP}$ & 0.54 & 0.93 & 1.73 & 0.22 & 0.81 & 3.77 \\
\hline & & {$[0.08]$} & {$[0.08]$} & [0.28] & [0.03] & {$[0.08]$} & [0.60] \\
\hline & $\mathrm{HP}$ & 0.78 & 1.14 & 1.46 & 0.27 & 0.93 & 3.46 \\
\hline & & [0.14] & {$[0.10]$} & {$[0.28]$} & [0.06] & [0.10] & [0.84] \\
\hline & $4 \mathrm{D}$ & 1.59 & 1.75 & 1.10 & 0.35 & 1.04 & 3.02 \\
\hline & & {$[0.28]$} & [0.12] & [0.21] & {$[0.07]$} & {$[0.08]$} & {$[0.65]$} \\
\hline \multirow[t]{6}{*}{ Mean } & $\mathrm{BP}$ & 0.49 & 0.54 & 1.10 & 0.20 & 0.47 & 2.39 \\
\hline & & {$[0.05]$} & {$[0.03]$} & [0.13] & {$[0.04]$} & {$[0.04]$} & [0.48] \\
\hline & $\mathrm{HP}$ & 0.66 & 0.83 & 1.27 & 0.23 & 0.68 & 3.02 \\
\hline & & [0.11] & {$[0.06]$} & [0.24] & {$[0.05]$} & {$[0.07]$} & [0.78] \\
\hline & $4 \mathrm{D}$ & 1.48 & 1.27 & 0.86 & 0.32 & 0.76 & 2.36 \\
\hline & & [0.14] & [0.11] & [0.11] & [0.05] & {$[0.09]$} & [0.46] \\
\hline
\end{tabular}

Usual hourly earnings newly hired workers (CPS)

\begin{tabular}{|r|r|r|r|r|r|r|r|}
\hline & & \multicolumn{3}{|c|}{ Std. Dev. } & \multicolumn{3}{|c|}{ Relative Std. Dev. } \\
\hline & & Pre-84 & Post-84 & Ratio & Pre-84 & Post-84 & Ratio \\
\hline Median & BP & 1.96 & 1.09 & 0.56 & 0.79 & 0.95 & 1.21 \\
& & {$[0.25]$} & {$[0.08]$} & {$[0.08]$} & {$[0.09]$} & {$[0.10]$} & {$[0.19]$} \\
\hline & $\mathrm{HP}$ & 5.08 & 2.94 & 0.58 & 1.75 & 2.40 & 1.37 \\
\hline & & {$[0.73]$} & {$[0.24]$} & {$[0.10]$} & {$[0.35]$} & {$[0.25]$} & {$[0.31]$} \\
\hline & $4 \mathrm{D}$ & 5.67 & 3.40 & 0.60 & 1.23 & 2.02 & 1.65 \\
\hline & & {$[0.63]$} & {$[0.27]$} & {$[0.08]$} & {$[0.18]$} & {$[0.25]$} & {$[0.31]$} \\
\hline Mean & $\mathrm{BP}$ & 1.42 & 0.67 & 0.47 & 0.57 & 0.58 & 1.03 \\
\hline & & {$[0.16]$} & {$[0.05]$} & {$[0.07]$} & {$[0.08]$} & {$[0.05]$} & {$[0.17]$} \\
\hline & $\mathrm{HP}$ & 3.54 & 2.31 & 0.65 & 1.22 & 1.88 & 1.54 \\
\hline & & {$[0.47]$} & {$[0.18]$} & {$[0.10]$} & {$[0.25]$} & {$[0.18]$} & {$[0.35]$} \\
\hline & 4D & 4.49 & 2.77 & 0.62 & 0.97 & 1.65 & 1.69 \\
\hline & & {$[0.60]$} & {$[0.26]$} & {$[0.10]$} & {$[0.17]$} & {$[0.24]$} & {$[0.38]$} \\
\hline
\end{tabular}

Standard errors in brackets are calculated from the variance-covariance matrix of the second moments using the delta method. CPS wage data are earnings per hour from the outgoing rotation groups, which limits the period for which quarterly data are available to after 1980. Wage series are constructed as in Haefke, Sonntag, and van Rens (2008) but are not corrected for composition bias for comparability with other data sources. However, keeping the composition of the labor force contant in terms of education, experience and demographic characteristics makes very little differerence for the results presented here. 
Extended Table 5. Additional Business Cycle Statistics

Volatility output and productivity (1949-2007)

\begin{tabular}{|r|r|r|r|r|r|r|r|}
\hline & & \multicolumn{3}{|c|}{ Std. Dev. } & \multicolumn{3}{|c|}{ Relative Std. Dev. } \\
\hline & & Pre-84 & Post-84 & Ratio & Pre-84 & Post-84 & Ratio \\
\hline Output & BP & 2.37 & 1.12 & 0.47 & & & \\
\hline & & {$[0.13]$} & {$[0.06]$} & {$[0.04]$} & & & \\
\hline & HP & 2.45 & 1.20 & 0.49 & & & \\
\hline & & {$[0.13]$} & {$[0.07]$} & {$[0.04]$} & & & \\
\hline & $4 D$ & 3.72 & 1.64 & 0.44 & & & \\
\hline /worker & & {$[0.18]$} & {$[0.16]$} & {$[0.05]$} & & & \\
\hline & BP & 1.36 & 0.81 & 0.60 & 0.57 & 0.72 & 1.26 \\
\hline & & {$[0.08]$} & {$[0.05]$} & {$[0.05]$} & {$[0.03]$} & {$[0.06]$} & {$[0.12]$} \\
\hline & & 1.48 & 0.85 & 0.58 & 0.60 & 0.71 & 1.18 \\
\hline & & {$[0.08]$} & {$[0.06]$} & {$[0.05]$} & {$[0.03]$} & {$[0.06]$} & {$[0.12]$} \\
\hline & $4 D$ & 2.50 & 1.26 & 0.51 & 0.67 & 0.77 & 1.15 \\
\hline /hour & & {$[0.14]$} & {$[0.08]$} & {$[0.04]$} & {$[0.03]$} & {$[0.07]$} & {$[0.13]$} \\
\hline & & 1.06 & 0.75 & 0.71 & 0.45 & 0.67 & 1.51 \\
\hline & & {$[0.06]$} & {$[0.06]$} & {$[0.07]$} & {$[0.03]$} & {$[0.07]$} & {$[0.18]$} \\
\hline & HP & 1.17 & 0.85 & 0.72 & 0.48 & 0.71 & 1.48 \\
\hline & & {$[0.07]$} & {$[0.06]$} & {$[0.07]$} & {$[0.03]$} & {$[0.07]$} & {$[0.18]$} \\
\hline & $4 D$ & 2.04 & 1.32 & 0.64 & 0.55 & 0.80 & 1.46 \\
\hline & & {$[0.13]$} & {$[0.08]$} & {$[0.06]$} & {$[0.03]$} & {$[0.09]$} & {$[0.19]$} \\
\hline
\end{tabular}

Correlations (1949-2007)

\begin{tabular}{|c|c|c|c|c|c|c|c|c|c|c|}
\hline & & \multicolumn{3}{|c|}{ Correlation with Output } & \multicolumn{3}{|c|}{ Correlation with Empl. } & \multicolumn{3}{|c|}{ Correlation with Hours } \\
\hline & & Pre-84 & Post-84 & Change & Pre-84 & Post-84 & Change & Pre-84 & Post-84 & Change \\
\hline \multirow[t]{6}{*}{ Employment } & $\mathrm{BP}$ & 0.84 & 0.70 & -0.14 & & & & & & \\
\hline & & {$[0.02]$} & [0.05] & [0.06] & & & & & & \\
\hline & $\mathrm{HP}$ & 0.81 & 0.74 & -0.07 & & & & & & \\
\hline & & {$[0.03]$} & [0.04] & [0.05] & & & & & & \\
\hline & $4 \mathrm{D}$ & 0.75 & 0.69 & -0.06 & & & & & & \\
\hline & & {$[0.03]$} & {$[0.05]$} & {$[0.06]$} & & & & & & \\
\hline \multirow[t]{6}{*}{ Hours } & $\mathrm{BP}$ & 0.90 & 0.79 & -0.11 & & & & & & \\
\hline & & {$[0.02]$} & {$[0.04]$} & {$[0.04]$} & & & & & & \\
\hline & $\mathrm{HP}$ & 0.88 & 0.81 & -0.07 & & & & & & \\
\hline & & {$[0.02]$} & {$[0.03]$} & {$[0.04]$} & & & & & & \\
\hline & $4 \mathrm{D}$ & 0.84 & 0.74 & -0.10 & & & & & & \\
\hline & & {$[0.02]$} & {$[0.05]$} & {$[0.05]$} & & & & & & \\
\hline \multirow[t]{6}{*}{ Wage } & $\mathrm{BP}$ & 0.40 & 0.28 & -0.12 & 0.20 & -0.11 & -0.31 & 0.22 & -0.09 & -0.31 \\
\hline & & {$[0.08]$} & {$[0.09]$} & {$[0.12]$} & [0.09] & {$[0.09]$} & {$[0.13]$} & {$[0.09]$} & {$[0.10]$} & {$[0.14]$} \\
\hline & $\mathrm{HP}$ & 0.37 & -0.01 & -0.38 & 0.23 & -0.31 & -0.54 & 0.21 & -0.31 & -0.52 \\
\hline & & {$[0.08]$} & [0.10] & {$[0.12]$} & {$[0.09]$} & {$[0.10]$} & {$[0.14]$} & [0.09] & {$[0.10]$} & [0.14] \\
\hline & $4 \mathrm{D}$ & 0.30 & 0.11 & -0.20 & -0.02 & -0.29 & -0.27 & 0.01 & -0.36 & -0.36 \\
\hline & & {$[0.07]$} & {$[0.07]$} & [0.10] & {$[0.07]$} & [0.08] & {$[0.11]$} & {$[0.07]$} & {$[0.08]$} & [0.11] \\
\hline
\end{tabular}

Standard errors in brackets are calculated from the variance-covariance matrix of the second moments using the delta method. See tables 1, 2 and 3 for data sources. 
Figure 5. The Rise of Temporary Help Services

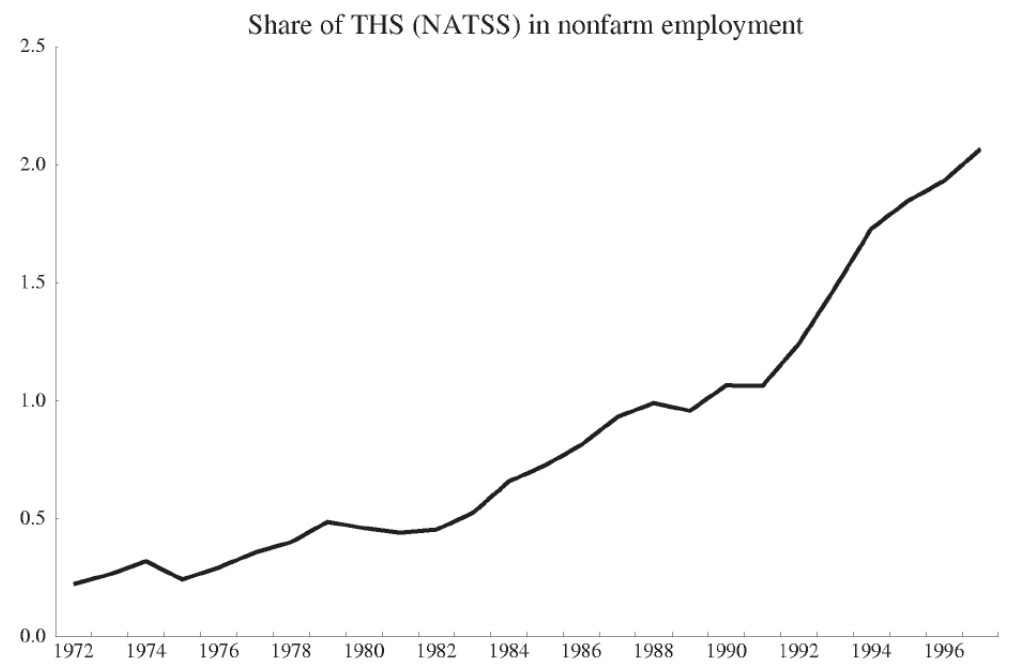

Source: Estevão and Lach (1999)

Figure 6. The Decline of Unions

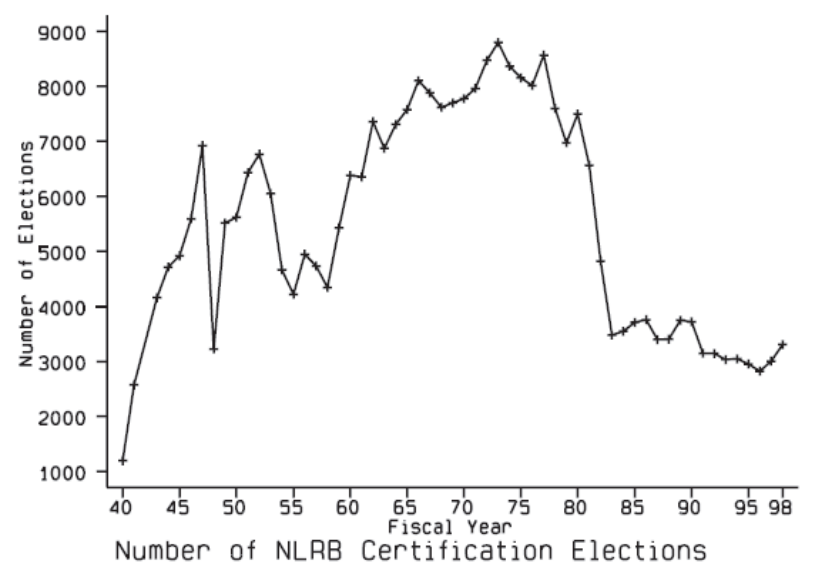

Source: Farber and Western (2002) 